Altorki et al

\title{
Evolution of immune escape mechanisms in the progression from preinvasive to
} invasive human lung adenocarcinoma.

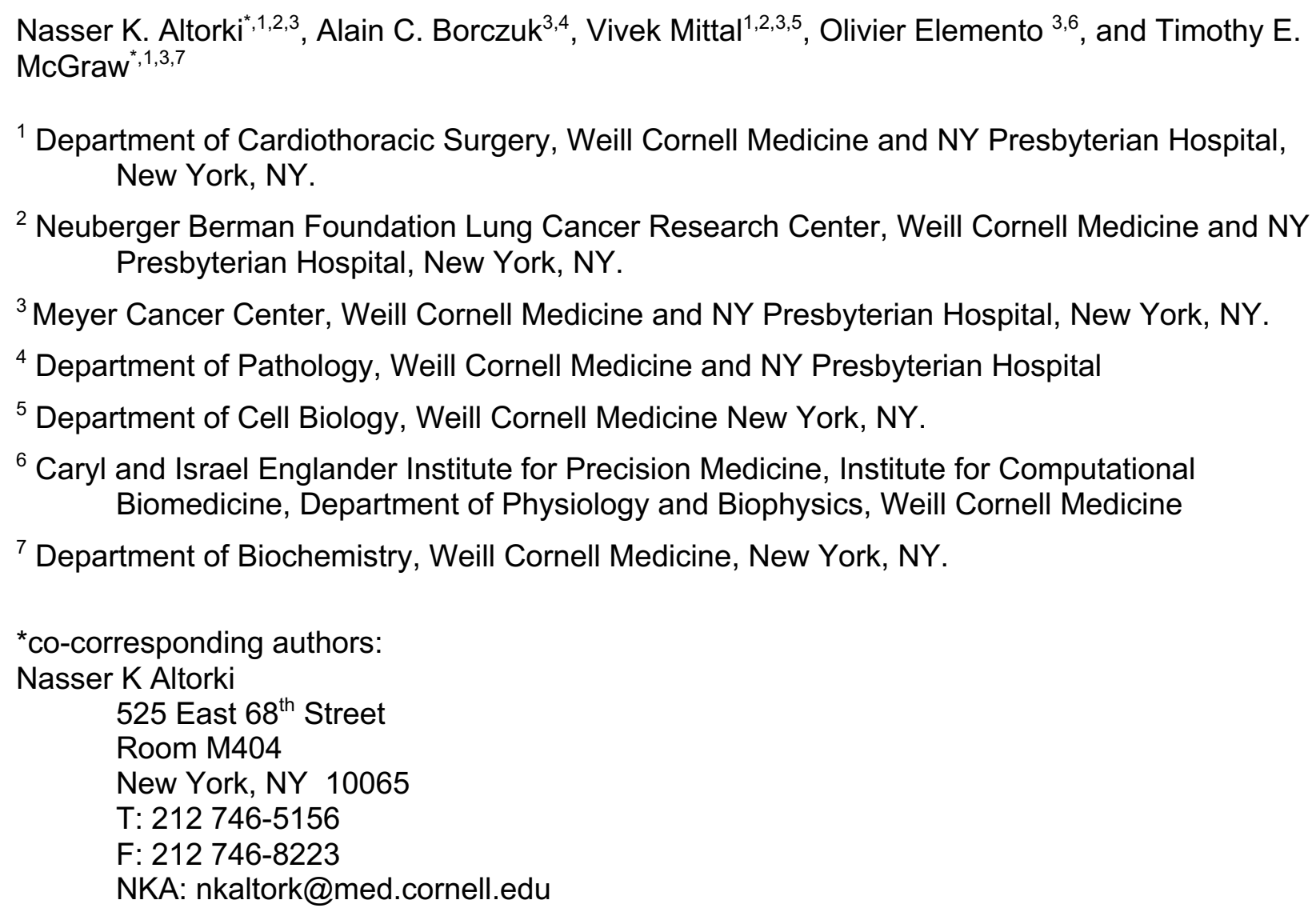

Statement of Significance: Using multiplexed IF, we compared the cellular composition and activation state of the tumor immune microenvironment between pre/minimally invasive and frankly invasive adenocarcinoma. We found a progressive increase in immunosuppressive mechanisms in association with disease progression suggesting that Interception strategies should be specifically tailored based on underlying immune escape mechanisms

Abbreviations: TME, tumor microenvironment; LUAD, lung adenocarcinoma; $p-N S$, Pure nonsolid; AIS, adenocarcinoma in-situ; MIA, minimally invasive adenocarcinoma; GZB, granzyme B; ROI, region of interest; CT, computer tomography; EGFR, EGF receptor; TMA, tumor microenvironment.

Running title: Evolution of immune escape mechanisms in lung adenocarcinoma Word count: Main text, 5560 words.

Figures: 7 in main text. Tables: 2 supplemental tables. 
Altorki et al

\section{6}

47

\section{Summary}

The tumor microenvironment (TME) of lung adenocarcinoma (LUAD) precursor lesions has not been described. We interrogated by multiplex immunofluorescence the TME of preinvasive and invasive Stage 1A LUADs selected by computer tomography (CT) scan-density. Pure non-solid ( $p-N S$ ) CT density nodules are preinvasive/minimally invasive, whereas solid CT density nodules are frankly invasive cancers. Our data reveal an intensely immune-suppressive immune TME in p-NS tumors characterized by an increase in Treg cells and a decrease in cytotoxic $T$ cells relative to normal lung. The TME of the solid tumor group, more advanced lesions than the p-NS yet still early in disease development, were increasingly more immune-suppressive. Provocatively, there was a further increase in both Treg cells and cytotoxic T cells, establishing a nascent albeit ineffective anti-tumor immune response in transition from preinvasive $p$ NS to invasive solid tumors. Regulatory T cells play a dominant role throughout progression, while additional immune evasive mechanisms are employed at different

60 stages of disease progression, including $T$ cell exclusion from cancer cell nests early 61 and activation of immune checkpoints later. Our study establishes that different immune62 targeted strategies are required to intercept disease progression at these two distinct early points of lung cancer development. 
Altorki et al

\section{INTRODUCTION}

The widespread use of computerized chest tomography (CT), particularly for lung cancer screening purposes, has led to the detection of ground-glass or non-solid nodules that are not visible on plain chest radiography. Non-solid nodules appear on CT scanning as hazy opacities that do not obscure the underlying lung parenchyma or vasculature. In most instances, nonsolid nodules less than $5 \mathrm{~mm}$ in size represent focal proliferative lesions known as atypical alveolar hyperplasia that are considered the earliest progenitor lesions of invasive adenocarcinoma of the lung. The majority of non-solid nodules, particularly those $\leq 3 \mathrm{~cm}$ in size, typically harbor adenocarcinoma in-situ (AIS) or minimally invasive adenocarcinoma (MIA) where the invasive component is $\leq 5 \mathrm{~mm}$ or less. Interestingly, $10-20 \%$ contain adenocarcinoma with an invasive component exceeding $5 \mathrm{~mm}$ suggestive of a more aggressive phenotype. Regardless, the precise biological behavior of these non-solid nodules remains unclear as many remain unchanged in size and appearance for many years. However, approximately $20-40 \%$ of these nodules grow or develop areas of increased CT density (a manifestation of more invasive malignancy) within a four-year window (1). Why some of these nodules retain an indolent behavior while others progress to invasive malignancy is unclear. This uncertainty commits patients to frequent, repeat imaging, and in some cases potentially harmful biopsies.

The critical role of the tumor microenvironment (TME) in tumorigenesis is well-recognized (2-5). The TME is predominantly composed of immune cells, fibroblasts and vasculature. There are a number of non-mutually exclusive hypotheses for how the TME contributes to tumorigenesis, one of which is "immunoediting" or "immune surveillance", a cancer cell-extrinsic mechanism that is engaged once cell-intrinsic killing mechanisms (e.g., apoptosis) have failed to eliminate individual transformed cells (6-8). The proposed temporal phases of cancer immune surveillance describing the homeostasis between cancer cell killing and survival include: elimination, equilibrium and escape (9). In the elimination phase, innate and adaptive immunity eliminate cancer cells before a tumor can emerge. In the equilibrium phase, immune cell killing of cancer cells is balanced by cancer cell proliferation, such that tumor growth is maintained in check, but the cancer cells are not fully eliminated. The escape phase is one of tumor growth due to cancer cells evading immune cell-mediated killing. Entry into the escape phase portends disease progression.

There are multiple mechanisms that may contribute to tumor progression, including the development of an overall immunosuppressive state in the TME and/or cancer cell driven escape mechanisms such as antigen loss or aberrations that impede antigen presentation such 
97 as downregulation of MHC class I or II molecules. Another mechanism invoked for immune

98 evasion is T cell exclusion from cancer cell nests attributed to organized fibroblastic proliferation

99 leading to physical and/or chemical barriers that restrict access of $\mathrm{T}$ cells to the cancer cell

100 nests. Any or all of the above mechanisms of immune escape may contribute to tumor

101 progression in a temporal and context dependent manner.

102 We posited that progression of lung cancer from preinvasive to invasive adenocarcinoma

103 develops as a result of immune escape mediated by a shift towards a more immune-

104 suppressive microenvironment. To test this hypothesis, we used multiplex immunofluorescence

105 to compare the cellular compositions and activation states of the TMEs of radiographically pure

106 non-solid nodules (preinvasive or minimally invasive lung cancer) to the TMEs of

107 radiographically solid (invasive lung cancer) nodules. Given the importance of CT appearance in

108 driving clinical decisions in management of lung nodules, we classified the groups based on

109 their radiographic appearance (10). Comparison of these two tumor groups captures changes

110 in the TME correlated with progression from preinvasive pure non-solid ( $p-N S$ ) to invasive solid

111 tumors. The characteristics of the TMEs of both p-NS and solid tumors are progressively more

112 immune suppressive than adjacent normal lung. Our findings demonstrate a diversity of

113 immune escape mechanisms at different phases during early development of human lung

114 adenocarcinoma (LUAD). 
Altorki et al

\section{Methods}

Samples and Tissue microarray. The samples for this IRB approved study were collected from the Weill Cornell lung nodule cohort, a retrospective collection of CT-imaged nodules with subsequent surgical resection and storage as formalin-fixed paraffin-embedded tissue. CT images were reviewed by 2 observers and classified as pure non-solid or solid nodules on CT attenuation. The corresponding surgical resections were reviewed for pathology, and invasion was measured using Aperio whole scanned slides. Faxitron x-ray of the paraffin blocks was used to identify the areas of lowest and highest tissue density for punch samples. Tissue microarrays slides of 3 ROls ( $1 \mathrm{~mm}$ diameter punch cores) per samples were generated. Normal tissue was obtained from separate paraffin blocks of tissue taken away from the tumor mass. The manual tissue arrayer (Beecher Instruments, Sun Prairie, WI) was used to generate tissue microarray (TMA) slides.

Multiplex imaging. The immunofluorescence imaging was performed using the Neogenomics platform as previously described (11). Briefly, formalin-fixed paraffin-embedded tissue arrays were baked at $65^{\circ} \mathrm{C}$ for $1 \mathrm{~h}$. Slides were deparaffinized with xylene, rehydrated by decreasing ethanol concentration washes, and then processed for antigen retrieval. A two-step antigen retrieval was adopted to allow antibodies with different antigen retrieval conditions to be used together on the same samples (12). Samples were then blocked against nonspecific binding with $10 \%(\mathrm{wt} / \mathrm{vol})$ donkey serum and $3 \%(\mathrm{wt} / \mathrm{vol})$ bovine serum albumin $(\mathrm{BSA})$ in phosphatebuffered solution (PBS) for $1 \mathrm{~h}$ at room temperature and stained with DAPI for $15 \mathrm{~min}$. Directly conjugated primary antibodies were diluted in PBS supplied with 3\% (wt/vol) BSA to optimized concentrations and applied for $1 \mathrm{~h}$ at room temperature on a Leica Bond III Stainer. In the case of primary-secondary antibody staining, samples were incubated with primary antibody, followed by incubation with species-specific secondary antibodies conjugated to either Cyanine 3 (cy3) or cyanine 5 (cy5).

Stained images were collected on INCell analyzer 2200 microscope (GE Healthcare Life Sciences) equipped with high-efficiency fluorochrome specific filter sets for DAPI, cy3 and cy5 (11) . For multiplexed staining where co-localization was desired, the regions of interest ( 0.4$0.6 \mathrm{~mm}^{2}$ tissue area) were imaged, and stage coordinates were saved. The coordinates of each image region were then recalled for each subsequent round after minor readjustment using reference points from the first-round DAPI image and determining the appropriate offset. The exposure times were set at a fixed value for all images of a given marker. For image analyses, 
Altorki et al

147 microscopy images were exported as full- resolution TIFF images in grayscale for each

148 individual channel collected.

149 MultiOmyx image analytics. The acquired images from sequential rounds were registered using

150 DAPI images acquired in the first round of staining via a rigid registration algorithm for each

151 region of interest. The parameters of transformation were then applied to the subsequent

152 rounds, which ensured that the pixel coordinates across all the imaging rounds corresponded to

153 the same physical locations on the tissue. Classification and co-expression analysis were

154 performed in multiple stages. First, a nuclear segmentation algorithm was applied on the DAPI

155 image to delineate and identify individual cells. Location information and expression of all the

156 markers were computed for every cell identified. Then, morphologic image analysis and shape

157 detection were performed using proprietary algorithms. These algorithms detect and classify

158 cells as positive or negative for each marker depending on their subcellular localization and

159 morphology. A tissue-quality algorithm was also applied to the images to ensure image artifacts

160 that arose owing to tissue folding or tear did not affect cell classification. Co-expression analysis

161 and phenotype identification were performed by combining individual marker classification

162 results.

163 aSMA Morphology. The aSMA morphology of 3 ROls per tumor were independently scored by

1642 investigators (NKA and TEM) as either organized (value of 1 ) or disorganized (value of 0 ).

165 Representative images of these 2 classes of morphology are shown in Figure 9. Each tumor

166 was assigned a predominant $\alpha$ SMA morphology based on the sum score: disorganized $\leq 1$;

167 organized $\geq 2$.

168 Statistical Analysis. Students unpaired T tests or Fishers exact test, where appropriate, were

169 used to evaluate group differences (Prism, GraphPad Software). All reported $p$ values are

170 significant based on Benjamini-Hochberg control for false discovery at an alpha of 0.05. 
Altorki et al

171

172

173

174

175

176

177

178

179

180

181

182

183

184

185

186

187

188

189

190

191

192

193

194

195

196

197

198

199

200

201

202

203

\section{RESULTS}

\section{Defining the tumor microenvironment by multiplex immunofluorescence analyses}

We used multiplex immunofluorescence microscopy to contrast the TME of both pure non-solid CT scan density ( $p-N S$ ) and solid early stage human LUADs. We generated a tissue microarray (TMA) of stage 1A LUADs: 25 p-NS tumors and 27 solid tumors (supplemental Table I). To capture the heterogeneity within individual tumors the TMA was constructed from different cores (regions of interests, ROI's) of each tumor. The expressions of all markers were determined in at least 3 ROls per tumor and some markers were measured in 6 ROls per tumor. A TMA of normal lung was generated from tissue adjacent to the tumors of 49 subjects (a single core per sample). The Neogenomics multiplex immunofluorescence platform (11) was used to quantify expressions of 19 markers to define the immune cell composition and activation states, to identify cancer/epithelial cells and fibroblasts (Fig. 1A and supplementalTable II). Briefly, the TMAs are stained with two different antibodies directly labeled with either Cy3 or Cy5

fluorophores. Images in both channels are collected, the Cy3 and Cy5 fluorescence inactivated, samples washed, stained with 2 new antibodies directly labeled with Cy3 or Cy5, images collected and the process repeated (12). In this iterative fashion the TMAs were stained with 20 antibodies. A representative multiplexed image is shown in figure $1 \mathrm{~B}$.

The CT density-defined groups were matched for age, sex and tumor size (supplemental Table I). In the p-NS group there were equal numbers of EGF receptor (EGFR) mutant and KRAS tumors (28\% each), whereas in the solid group there were 3 times as many KRAS $(37 \%)$ as mutant EGFR tumors (11\%). Within the constraints of our sample size, we were unable to detect a significant differences in the immune compositions of KRAS and mutant EGFR TMEs, either within a tumor group or between the two tumor groups. Tumors in the CT solid group were significantly more invasive than the p-NS tumors (Fig. 1C), supporting the use of CT density as a means to classify tumors for analyses of how the TME changes with tumor progression. The percentage of $\mathrm{Ki} 67^{+}$panCK cells in the solid tumor group was significantly increased relative to the p-NS, confirming that the CT dense tumors are more proliferative (Fig. 1D).

p-NS and solid tumors are equally T cell inflamed compared to normal lung

T cell density (CD3 ${ }^{+}$cells) was significantly elevated in both the p-NS and solid tumor groups compared to the normal lung group, whereas there was no significant difference in $T$ cell density between p-NS and solid tumor groups (Fig. 1E). Therefore, neither the emergence of a p-NS tumor from normal lung nor the progression from $\mathrm{p}-\mathrm{NS}$ to solid tumors are characterized by 
Altorki et al

204 exclusion of T cells from the tumor mass. In addition, intra-tumor heterogeneity in T cell

205 densities, assessed by the coefficient of variation of T cell density among the 6 ROls per tumor,

206 were similar in the two tumor groups, establishing that intra-tumor heterogeneity in T cell density

207 does not change significantly during progression of p-NS to solid tumors (Fig. 1F).

208 To broadly define the TME of the groups, we also determined the density of B cells (CD3-CD19 ${ }^{+}$ 209 cells), macrophages (CD3 ${ }^{-}$CD68 $^{+}$CD209- $^{-}$cells), dendritic cells (CD3- CD209 ${ }^{+}$CD68 $^{-}$cells) and

210 fibroblasts (CD3- panCK ${ }^{-} \alpha \mathrm{SMA}^{+}$cells). Alpha smooth muscle actin ( $\alpha \mathrm{SMA}$ ) is frequently used as

211 a marker of cancer-associated fibroblasts, although it is expressed in other cell types, most

212 prominently myofibroblasts and pericytes (13). Here we refer to $\alpha \mathrm{SMA}^{+}$cells as fibroblasts. B

213 cell density in the normal lung was low (0.06\% of total cells) and significantly elevated in both p-

214 NS and solid tumor groups (2.7\% and $2.1 \%$ of total cells, respectively) (Fig. 1G). However, there

215 was no significant difference in B cell density between the two tumor groups. There was a small

216 yet significant reduction in macrophage cell density in the solid tumor groups compared to

217 normal lung, whereas there was no difference between the p-NS group and the normal lung

218 (Fig. 1H). Neither the dendritic cell density nor fibroblast cell density varied significantly among

219 the three groups (Fig. 1 I \& J).

\section{The TMEs of $p-N S$ tumors are enriched for Treg cells}

221 We investigated the T cell subtype compositions to determine whether the TME of $p-N S$ tumors

222 were predominantly immune-suppressive. $\mathrm{CD}^{+} \mathrm{T}$ cells $\left(\mathrm{CD} 3^{+} \mathrm{CD} 4^{+}\right)$were significantly

223 increased in the p-NS tumor group (Fig. 2A). The subtype composition of the CD4 ${ }^{+} \mathrm{T}$ cells also

224 varied between the normal lung and p-NS tumor groups. Immune-suppressive Treg cells (CD3 ${ }^{+}$

$225 \mathrm{CD}^{+} \mathrm{FoxP}^{+}$cells) were significantly increased in the $\mathrm{p}-\mathrm{NS}$ tumor group at the expense of $\mathrm{T}$

226 helper cells (CD3 ${ }^{+} \mathrm{CD}^{+}$FoxP3- cells) and approximately $5 \%$ of the Treg cells in the p-NS group

227 were $\mathrm{Ki} 67^{+}$(Fig. 2B\&C). Importantly, CTLA-4+ ${ }^{+}$Treg cells were enriched in the p-NS tumor group

228 compared to normal lung, approximately $2 \%$ of which were Ki67 $7^{+}$(Fig. 2D\&E). CTLA-4

229 expression is associated with enhanced Treg activity and homeostasis $(14,15)$. These data

230 demonstrate an increased immune-suppressive TME in p-NS tumor group compared to normal

231 lung.

232 The density of cytotoxic $\mathrm{T}\left(\mathrm{CD} 3^{+} \mathrm{CD} 8^{+}\right)$cells, as the proportion of $\mathrm{T}$ cells, did not differ between

233 normal lung and p-NS tumor groups (Fig. 2F). However, granzyme B (GZB) expressing

234 cytotoxic cells $\left(\mathrm{GZB}^{+} \mathrm{CD} 8^{+} \mathrm{CD} 3^{+}\right.$cells) were reduced in the $\mathrm{p}-\mathrm{NS}$ tumor group relative to normal

235 lung (Fig. 2G). GZB expression distinguishes active from resting or memory cytotoxic T cells. In 
236 addition, less than $1 \%$ of the active cytotoxic T cells in the p-NS tumor group were positive for 237 the proliferation marker Ki67 (Fig. 2H). The ratio of Treg cells to cytotoxic T cells per individual

238 sample was significantly elevated in the p-NS group that the normal lung group (Fig. 2I),

239 supporting the hypothesis that in individual p-NS tumors both an increase in Tregs and a

240 decrease in CD8 T cells contribute to an immune-suppressive TME.

241 Expression of immune checkpoints is a mechanism by which tumors evade immune-mediated

242 killing (16). There was no difference between normal lung and $\mathrm{p}-\mathrm{NS}$ tumor groups in two

243 immune checkpoints known to be upregulated in LUADs (13): PD-L1+ ${ }^{+}$or TIM-3 ${ }^{+}$(Fig. 2J\&K). In

244 addition, there was no difference in $\mathrm{PD} 1^{+} \mathrm{T}$ cells, whose expression is often used as marker of $\mathrm{T}$

245 cell exhaustion/dysfunction (17) (Fig. 2L). MHC class I ${ }^{+}$cell density $\left(\mathrm{HLA}-\mathrm{ABC}^{+}\right.$) was elevated

246 in the p-NS tumors, demonstrating that reduced MHC class I antigen presentation is not a

247 mechanism for immune escape in p-NS tumors (Fig. 2M). There was no difference between

248 normal lung and p-NS tumor group in MHC class II expression (HLA-DR ${ }^{+}$cells) (Fig. 2N).

249 However, there was an increase in the p-NS tumor group of CD45RO+ cells, a marker of

250 memory T cells, consistent with an increase in antigen-experienced cells in the p-NS tumors

251 (Fig. 20).

252 Our analyses of the immune TME of $p$-NS tumors compared to adjacent normal lung support 253 the hypothesis that in the p-NS tumors, an early manifestation of LUAD, cancer cells evade 254 immune-mediated cell killing predominately through mechanisms involving a TME enriched with 255 immune-suppressive Treg cells and depleted for activated cytotoxic T cells.

Increased active Treg cells and cytotoxic T cells in the solid tumor group

257 We next compared the immune-TME of the p-NS and solid tumor groups by assessing the 258 composition and activation states of the T cells. There was no difference in $\mathrm{CD} 3^{+} \mathrm{CD} 4^{+}$cell 259 density between p-NS and solid tumor groups, regardless of whether CD4 ${ }^{+}$cells were analyzed 260 as the percent of total cells or as the percent of $\mathrm{CD}^{+}$cells (Fig. 3A \& B). In both tumor groups 261 about $70 \%$ of the T cells were $\mathrm{CD} 4^{+}$cells. However, the proportions of $\mathrm{CD} 4^{+}$cells that were 262 immune-suppressive Treg cells were significantly increased in the solid tumor group (Fig. 3C). 263 An equal proportion of Tregs were $\mathrm{Ki} 7^{+}$in both groups (Fig. 3D). However, the proportion of 264 CTLA $-4^{+}$Treg cells was significantly elevated in the solid tumor group, consistent with an 265 increased immune-suppressive TME of solid tumors relative to the p-NS tumors (Fig. 3E). 
266 There was no significant difference in cytotoxic T cell $\left(C D 3^{+} C D 8^{+}\right)$density between the groups 267 when measured as a proportion of total cells (density in tissue) or as a proportion of CD ${ }^{+}$cells 268 (Fig. 3F\&G). There was, unexpectedly, an increase in activated cytotoxic T cells $269\left(\mathrm{CD}^{+} \mathrm{CD}^{+} \mathrm{GZB}^{+}\right)$as well as $\mathrm{Ki}^{+} 7^{+}$active CD8 cells in the solid tumor group (Fig. 3H\&I). Thus, 270 there is an active cytotoxic immune response in the more advanced solid tumors. The 271 corresponding increase in immune-suppressive Treg cells may serve to counter-balance the 272 increase in cytotoxic cells, thereby contributing to a blunting of activated cytotoxic T cells.

273 Supporting that hypothesis, there was a positive correlation between the densities of Treg cells 274 and $\mathrm{GZB}^{+} \mathrm{CD} 8$ cells in the solid tumor group (Fig. 3J).

275 We explored other potential immune-suppressive mechanism to account for the suppression of 276 cytotoxic T cell response in the solid tumor group. There were no differences between the p-NS 277 and solid tumor groups in PD1 ${ }^{+}$checkpoint expression in cytotoxic T cells (PD1 $\left.{ }^{+} \mathrm{CD} 8^{+}\right)$(Fig. 4A). 278 Hence, cytotoxic T cell "exhaustion" does not underlie immune suppression of the TME in solid 279 tumors. There was, however, an increase in PD1 ${ }^{+}$Thelper cells (PD1 ${ }^{+} \mathrm{CD}^{+} \mathrm{CD}^{+}{ }^{+} \mathrm{FoxP3}^{-}$), 280 indicating potential checkpoint-mediated blunting of $\mathrm{T}$ helper function contributing to the immune 281 suppressive TME of solid tumors (Fig. 4B). There was no difference in expression of the TIM3 $^{+}$ 282 checkpoint between the groups (Fig. 4C).

283 The densities of $\mathrm{MHC}$ class I-expressing cells $\left(\mathrm{HLA}-\mathrm{ABC}^{+}\right)$were not different between the two 284 tumor groups, demonstrating that in the more advanced solid tumors, cancer cells do not evade 285 immune surveillance by reduced MHC class I antigen presentation (Fig. 4D). There were no 286 differences in MHC class II expressing macrophages (HLA-DR ${ }^{+}$CD68 ${ }^{+}$CD3-CD209-) nor 287 dendritic cells (HLA-DR ${ }^{+}$CD209 ${ }^{+}$CD3-CD68 ${ }^{-}$) between the groups (Fig. 4E\&F).

288 Upregulation of the tryptophan catabolic enzyme, indoleamine 2,3-dioxyhydrogenase (IDO), can 289 have an immune suppressive role in cancer (16). Because IDO can be expressed by either 290 cancer cells or cells of the tumor stroma, we compared the p-NS and solid tumor groups for total 291 IDO expressing cells (Fig. 4G). There was no difference in IDO expression between the tumor 292 groups, although two solid tumors expressed IDO at a higher frequency than the others.

293 Although IDO expression might have an immune suppressive role in these two solid tumors, 294 increased IDO expression does not underlie enhanced immune suppression in the solid tumor 295 group compared to the p-NS tumor group (inset Fig. 4G). 
Altorki et al

296 Arginase 1, expressed by cells of the TME, has an inhibitory effect on antigen-specific anti-

297 tumor T cell responses (18). As was the case for IDO, Arginase expression does not distinguish

298 the tumor groups, therefore Arginase I upregulation is not a common immune-suppressive

299 mechanism in the solid tumor group (Fig. 4H). The frequency of arginase expression is

300 elevated in 2 of the solid tumors (not the same as those in which IDO is upregulated),

301 suggesting elevated Arginase might in some tumors have an immune suppressive role.

302 Heterogenous expression of PD-L1 among the solid tumor group

303 Expression of the PD-L1 checkpoint is a mechanism for immune escape in NSCLC and the

304 percent of cancer cells expressing PD-L1 is used clinically to assess overall PD-L1 expression

305 in tumors (19). In the p-NS tumor group only 3 of 25 tumors had greater than $1 \%$ PD-L $1^{+}$panCK

306 cells, whereas in the solid tumor group 13 of 29 had greater than 1\% PD-L1+ panCK cells (Fig.

$3075 A \& B)$. Because of the broad range of PD-L1 expression among the solid tumors, we

308 segregated them into three groups: tumors with less than 1\% PD-L $1^{+}$panCK cells; tumors with

309 less than $50 \%$ PD-L $1^{+}$panCK cells; tumors with greater than $50 \% \mathrm{PD}-\mathrm{L} 1^{+}$panCK cells. Total

310 tumor-mass infiltrating T cells did not correlate with PD-L1 expression but higher PD-L1

311 expression in panCK cells correlated with an increase in activated cytotoxic $T$ cells

$312\left(\mathrm{CD}^{+} \mathrm{CD}^{+} \mathrm{GZB}^{+}\right)$and CTLA-4 ${ }^{+}$Tregs $\left(\mathrm{CD}^{+} \mathrm{CD} 4^{+} \mathrm{FoxP} 3^{+}\right)$(Fig. 5C-E). No differences in the

313 immune profiles of the low and intermediate PD-L1 expressing tumor groups were detected.

314 Thus, a high percentage of PD-L1 expressing panCK ${ }^{+}$cells was linked to increases in both

315 immune suppressive and cytotoxic T cells. These data support the hypothesis that an anti-

316 cancer cytotoxic $T$ cell immune response was blunted by both the immune suppressive activities

317 of Treg cells and an increase PD-L1 expression.

318 There was a positive correlation between PD-L1 expression in panCK ${ }^{+}$cells and PD-L1

319 expression in T cells as well as fibroblasts within the same tumors (Fig. 5F). Thus, upregulation

320 of PD-L1 is not restricted to cancer cells (panCK ${ }^{+}$cells) but rather enhanced PD-L1 expression

321 reflects conditions within the TME.

322 Expression of PD1 was increased in cytotoxic T cells of the high PD-L1 expressing tumor group

323 (Fig. 5G). PD1 expression was increased in Thelper cells of tumors in the highest PD-L1

324 expressing group compared to the intermediate and no PD-L1 expressing tumor groups (Fig.

325 5H). There were no differences among the groups in PD1+ Tregs (Fig. 5I). PD1, a negative

326 feedback receptor, is expressed on both activated and "exhausted" $T$ cells, and therefore its

327 expression alone does not establish the activated state of T cells. However, high PD1 
328 expression in an environment of high PD-L1 expression indicates active checkpoint function.

329 Consequently, in the high PD-L1 expressing tumor group, both the anti-tumor T helper and

330 cytotoxic T cells are likely to be suppressed, relative to the lower PD-L1 expressing tumor 331 groups.

332 T Cell exclusion from cancer cell nests as an immune-suppressive mechanism in p-NS tumors

333 The spatial distribution of T cells within the tumor mass, either localized to the stroma or

334 infiltrated among the cancer cells nests, impacts immune response to the cancer cells since the 335 physical proximity of $T$ cells to cancer cells is required for cytotoxic $T$ cell function. Restriction of 336 intra-tumoral $\mathrm{T}$ cells to the stroma (fibroblast-rich) and exclusion from the parenchyma is a 337 mechanism for evasion of immune surveillance $(2,5,20,21)$.

338 We quantified the spatial distribution of T cells within the stroma or cancer cell nests based on a 339 panCK ${ }^{+}$mask. A frequency distribution histogram based on T cell infiltration of cancer cell beds

340 (percent total tumor T cells) revealed increased T cell infiltration in the solid tumor group (Fig.

$3416 \mathrm{~A}$ ). To explore differences in the immune composition based on localization within the tumor

342 (that is, stroma or cancer cell nests), we used a value of greater than or equal to $5 \%$ of $\mathrm{T}$ cells

$343\left(\mathrm{CD}^{+}\right)$within cancer cells nest to segregate tumors into 'high' and 'low' T cell infiltration of

344 cancer cell nests (Fig. 6A). There was a trend towards increased infiltration of T cells among the

345 cancer cell nests in the solid tumor group: $74 \%$ of the solid tumors and $52 \%$ of the p-NS had

346 high T cell infiltration of the cancer cell nests ( $p=0.15$, Fischer's Exact Test). However,

347 differences in the compositions of the T cells within the cancer cells nests between the two

348 tumor groups were similar to those differences in the tumor not segregated for location, with an

349 increase of both Treg cells and cytotoxic cells in the solid tumor group (Fig. 6B\&C).

350 T cell infiltration into the cancer cell nest of the solid tumors was highest in those tumors with

351 the highest PD-L1 expression, in line with induced PD-L1 expression protecting the cancer cells

352 from the cytotoxic T cells that had invaded the cancer cell nest (Fig. 6D). There were no

353 differences in total tumor-mass infiltrating T cells between the p-NS and solid tumor groups (Fig.

354 1E). Therefore, exclusion of the T cells from the cancer cell nests, rather than from the tumor 355 mass per se, is potentially a more important mechanism for immune escape in the p-NS tumor 356 group than it may be in the solid tumor group.

357 Fibroblasts morphology varies between the $\mathrm{p}-\mathrm{NS}$ and solid tumors groups 
358 Staining for alpha smooth muscle actin ( $\alpha \mathrm{SMA})$ as a marker of fibroblasts revealed two 359 prominent morphologies represented in both tumor groups. In one, the $\alpha$ SMA was well

360 organized, circumscribing the cancer cell nests (panCK ${ }^{+}$) (Fig. 7A\&B). In the other the $\alpha$ SMA

361 pattern was disorganized and fragmented (Fig. 7C\&D). The disorganized fibroblasts structure

362 ( $\alpha$ SMA morphology) was significantly more prevalent in the solid tumors (Fig. 7E). These data

363 associate a disorganized $\alpha$ SMA morphology with the more advanced tumor group.

364 Furthermore, in the p-NS tumor group the degree of T cell infiltration among the cancer cells

365 was significantly decreased in tumor areas (ROIs) of organized $\alpha$ SMA morphology, correlating

366 the intact fibroblastic structure with reduced accumulation of $\mathrm{T}$ cell among the cancer cells, a

367 correlation not observed in the solid tumors (Fig. 7F). 
Altorki et al

368

369

370

371

372

373

374

375

376

377

378

379

380

381

382

383

384

385

386

387

388

389

390

391

392

393

394

395

396

397

398

399

400

\section{DISCUSSION}

Immune escape is essential for tumor progression, and a more thorough understanding of the cellular and molecular mechanism(s) by which preinvasive malignancies escape immune surveillance may allow for the development of more effective interception strategies that can be deployed at the earliest manifestations of disease (20-22). Currently there are significant gaps in our understanding of the molecular and cellular events driving immune escape in preinvasive lung lesions. Although there have been recent reports on the genomic and transcriptomic landscapes of preinvasive squamous cell cancer $(23,24)$ there are only a few studies of preinvasive pulmonary adenocarcinoma, and even fewer that focused on the immune milieu in tumor microenvironment. The most comprehensive profiling of the TME, reported by Lavin et al, was focused on clinically evident early lung cancers rather than precursor lesions (25). A more recent report by Chen et al, reported on 98 precursor lesions of lung adenocarcinoma and found that immune infiltration is correlated with copy number alterations of chromosome arm $6 p$ suggesting a link between arm-level events and the tumor immune environment (26). Our limited understanding of the early events associated with progression of precursor lesions of LUAD is at least partly due to the difficulty in accessing sufficient material from these small lesions in humans for study. Typically, LUAD precursor lesions are situated peripherally in the lung parenchyma where they are inaccessible by bronchoscopic approaches and therefore tissue sampling is only possible after surgical removal. In this study we contrasted two extremes on the radiographic spectrum, the pure non-solid nodule which generally (but not always) harbors pre or minimally invasive adenocarcinoma and the solid nodule representing frankly invasive cancers. The choice of extremes was designed to allow us to maximize and capture significant molecular events associated with transition to a more invasive phenotype.

\section{Evolution of preinvasive adenocarcinoma in pure non-solid tumors}

We found that compared to adjacent normal lung, the stroma of p-NS tumors was intensely infiltrated by immune cells, an infiltration predominantly composed of $\mathrm{CD} 3^{+} \mathrm{T}$ cells. The composition of the $\mathrm{CD}^{+}$population was dominated by $\mathrm{CD} 4^{+}$cells that accounted for nearly two thirds of all T cells within the tumor nodule. Significantly, immune-suppressive regulatory $T$ cells $\left(\mathrm{CD}^{+} \mathrm{CD}^{+} \mathrm{FoxP}^{+}\right)$were twice as prevalent in the $\mathrm{p}$-NS tumor group than in normal lung (Fig. 2). Approximately $10 \%$ of the Tregs in p-NS group expressed the activation marker CTLA-4, whereas less than $1 \%$ of Tregs in normal lung were CTLA $-4^{+}$(Fig. 2). Although, the proportion of cytotoxic T cells $\left(\mathrm{CD}^{+} \mathrm{CD} 8^{+}\right)$in the p-NS tumor nodule group was essentially the same as in normal lung, the proportion of $\mathrm{GZB}^{+} \mathrm{CD} 8^{+} \mathrm{T}$ cells was almost three-fold lower than that in normal 
401 lung and nearly all lacked Ki67 expression, suggesting a possible exhausted phenotype (Fig. 2).

402 On a per tumor basis, the Treg cell-to-CD8 ${ }^{+}$cell ratio was significantly higher in the tumor

403 nodule than in normal lung, indicating the dominance of Treg-mediated immunosuppressive

404 effect. We also found that the expression of MHC class I molecules and CD45RO ${ }^{+}$cells were

405 significantly higher in tumor nodules than in normal lung, demonstrating that escape from

406 immune surveillance was not mediated by aberration in antigen presentation (Fig. 2).

407 Interestingly, expression of the inhibitory checkpoints PD1, PD-L1 and Tim-3, were not

408 upregulated in the p-NS tumor group, suggesting that immune privilege of $\mathrm{p}$-NS nodules does

409 not result from activation of inhibitory immune checkpoints.

410 Evolution of early solid invasive adenocarcinoma

411 We made several observations when comparing the immune TME profile of lung

412 adenocarcinoma presenting as a solid tumor with that arising in p-NS nodules. Our findings

413 strongly support the hypothesis that multiple modes of tumor escape develop during transition to

414 an invasive phenotype. First, although adenocarcinomas arising in both types of nodules were

415 equally T cell inflamed (Fig. 1), those in solid nodules had a significantly higher proportion of

416 regulatory $T$ cells, with a two-fold increase in the proportion of immune suppressive Treg cells

$417\left(\mathrm{CD}^{+} \mathrm{CD}^{+}{ }^{+} \mathrm{FoxP}^{+}\right)$that expressed CTLA-4 (Fig. 3). There was also an associated three-fold

418 increase in the number of activated cytotoxic T cells $\left(\mathrm{GZB}^{+} \mathrm{CD} 8^{+}\right)$cells in the solid tumors (Fig.

419 3), suggesting a nascent albeit ineffective anti-tumor immune response. It is likely that any

420 emergent anti-tumor immune response may have been at least partially restrained by Treg cell-

421 mediated immune suppression. In the context of the immune editing hypothesis for tumor

422 progression, these data indicate that the transition from p-NS to solid nodules reflects a shift

423 from equilibrium to escape phase of immune editing (9). Second, while there was essentially no

424 PD-L $1^{+}$expression in panCK ${ }^{+}$cells of the $\mathrm{p}-\mathrm{NS}$ group, collectively solid nodules had a

425 significantly higher frequency of PD-L1+ panCK ${ }^{+}$cells (Fig. 5). Thus, expression of the PD-L1

426 inhibitory immune checkpoint, an established mode of immune evasion potentially deployed by

427 cancer cells possibly due to the release of interferon gamma from activated cytotoxic $T$ cells,

428 was only observed in more advance tumors.

PD-L1 expression defines two immune phenotypes of solid adenocarcinoma

430 PD-L1 expression in panCK ${ }^{+}$adenocarcinoma presenting as a solid nodule identified three

431 distinct sub-groups based on the frequency of PD-L1 expression. Tumors in which $50 \%$ or more

432 of the panCK ${ }^{+}$cells expressed PD-L1, a threshold commonly used in the clinic for treating stage

433 IV lung cancer patients with anti-PD-1 alone (that is, without chemotherapy), were grouped as 
434 high PD-L1 expressers. Tumors in which greater than $1 \%$ but less than $50 \%$ of the panCK

435 were PD-L1+ ${ }^{+}$were classified as a separate group as were those in which PD-L1 expression in

436 panCK ${ }^{+}$was less than 1\%. Tumors with high PDL-1 expression in panCK ${ }^{+}$cells were associated

437 with higher PD-L1 expression in various T cell subsets and fibroblasts. High expressers had a

438 distinctive immune phenotype characterized by more intense T cell infiltration, and broad

439 activation of the adaptive immune response, including significantly higher frequencies of PD1 ${ }^{+}$

440 cytotoxic $\mathrm{T}$ cells $\left(\mathrm{CD}^{+} \mathrm{CD}^{+} \mathrm{GZB}^{+}\right)$and $\mathrm{PD} 1^{+}$cytotoxic $\mathrm{T}$ helper cells $\left(\mathrm{CD} 3^{+} \mathrm{CD} 4^{+} \mathrm{FoxP}^{-}\right)$and

$441 \mathrm{CTLA}^{-} 4^{+}$Treg cells $\left(\mathrm{CD} 3^{+} \mathrm{CD} 4^{+} \mathrm{FoxP}^{+}\right)$. This defines tumors that are most likely to respond to

442 dual immune check point inhibition targeting CTLA-4 and/or the PD1/PDL-1 axis. There was no

443 significant difference in either the composition or activation state of immune cells of the TME

444 between low and intermediate expressers of PD-L1, which might reflect a relatively quiescent

445 immune response. In this group of patients, response to immune checkpoint inhibition alone

446 may be unlikely and this is reflected to some extent in clinical practice where such patients are

447 treated by a combination of chemotherapy and immune checkpoint inhibition (27).

\section{T cell infiltration into the cancer cell nests is also immune-suppressive}

449 The phenomenon of T cell exclusion has been previously reported as a mechanism of immune

450 evasion in multiple cancers including pancreatic, ovarian and colorectal cancer (28-30). A

451 similar finding was observed in ductal carcinoma in-situ breast cancer where cancer cells are

452 separated from tumor infiltrating T cells by a continuous layer of myoepithelial cells and

453 myofibroblasts (31). T cell exclusion from the entire tumor mass was not observed in any of our

454 cases. However, T cell exclusion from the cancer cell nests was observed in nearly $50 \%$ of all

455 tumor nodules classified radiographically as p-NS and in $25 \%$ of solid nodules that represented

456 frankly invasive adenocarcinoma. In all remaining cases there was infiltration of $\mathrm{CD}^{+} \mathrm{T}$ cells

457 into the cancer cell nests where they were interspersed with the cancer cells. The immune

458 phenotype of the T cells in the cancer cell nests mirrored that of $\mathrm{CD}^{+} \mathrm{T}$ cells in the stroma and 459 was dominantly immune suppressive.

\section{Fibroblastic architecture possibly associated with T cell exclusion}

461 To investigate whether fibroblastic spatial organization is associated with $\mathrm{T}$ cell exclusion we

462 scored each tumor for continuity of $\alpha$ SMA staining. The fibroblastic barrier appeared continuous

463 in $26 \%$ of all solid tumor nodules and interrupted or discontinuous in the remaining $74 \%$. In the

464 latter cases the CD3 cells were predominantly interspersed among the cancer cells. In contrast, 465 in p-NS tumors the barrier was continuous in three quarters of patients and discontinuous in the 
466 remainder. We found that a continuous fibroblastic barrier was significantly associated with $\mathrm{T}$

467 cell exclusion in p-NS tumor group but not in the solid nodule group, probably because the

468 majority of solid nodules had a discontinuous barrier. Whether T cell exclusion in our samples

469 was the result of a mere physical structural separation or alternatively mediated by specific

470 chemokine/receptor signaling or both remains to be elucidated. Fearon and co-workers have

471 shown that ligation of CXCL12 expressed on cancer associated fibroblasts to its receptor

472 CXCR4 on cancer cells may contribute to T cell exclusion in pancreatic adenocarcinoma (32).

473 In summary, our data suggest a complex dynamic interaction between the tumor and its

474 immune microenvironment (Fig. 7G). A dominant regulatory T cell-mediated immune

475 suppression is initiated at the precursor level and is sustained with rising intensity throughout

476 malignant progression. T cell exclusion from the cancer cell nests appears to be an additional

477 mechanism of immune evasion deployed by some early invasive lung cancers, possibly until

478 tumor evolution leads to a durable, viable invasive phenotype that breaks down the fibroblastic

479 barrier. Throughout the entire process a nascent effector immune response is present but is

480 effectively thwarted by the immune-suppressive elements. These data suggest that different

481 interception strategies should be employed at different stages of tumor evolution. 
482 Acknowledgements: The multiplex immunofluorescence was performed through a fee-for-

483 service contract with Neogenomics Laboratories, Inc (Fort Myers, FL). The study was supported

484 by UG3 CA244697 (NKA, ACB, VM, OE and TEM), the Yoram Cohen family foundation (NKA),

485 Vicky and Jay Furhman family fund (NKA) and the WCM Meyer Cancer Center (NKA, TEM). In

486 addition, OE is also supported by UL1TR002384, R01CA194547, LLS SCOR grants 180078-02,

487 7021-20. We thank Gary Koretzky (WCM), Niroshana Anandasabapathy (WCM) and Juan

488 Cubillos-Ruiz (WCM) for helpful discussions and critical reading of the manuscript.

489 Author disclosures: NKA has equity in Angiocrine Bioscience, TMRW, and View Point

490 Medical. OE is supported by Janssen and Eli Lilly research grants. He is scientific advisor and

491 equity holder in Freenome, Owkin, Volastra Therapeutics and One Three Biotech. TEM receives

492 research funding from Pfizer, Inc for unrelated studies. VM and ACB have nothing to disclose.

493

494 Author contributions:

495 NKA: conceptualized the project, contributed to experimental design, performed analysis and 496 interpretations, and wrote the manuscript.

497 ACB: contributed to experimental design, data analyses, and edited the manuscript.

498 VM: contributed to experimental design and edited the manuscript.

499 OE: contributed to experimental design, data analyses, and edited the manuscript.

500 TEM: conceptualized the project, contributed to experimental design, performed analysis and 501 interpretation, and wrote the manuscript. 
Altorki et al

\section{References}

1. Kobayashi Y, Mitsudomi T. Management of ground-glass opacities: should all pulmonary lesions with ground-glass opacity be surgically resected? Transl Lung Cancer Res 2013;2(5):354-63 doi 10.3978/j.issn.2218-6751.2013.09.03.

2. Klemm F, Joyce JA. Microenvironmental regulation of therapeutic response in cancer. Trends Cell Biol 2015;25(4):198-213 doi 10.1016/j.tcb.2014.11.006.

3. Pyonteck SM, Akkari L, Schuhmacher AJ, Bowman RL, Sevenich L, Quail DF, et al. CSF-1R inhibition alters macrophage polarization and blocks glioma progression. Nat Med 2013;19(10):1264-72 doi 10.1038/nm.3337.

4. Turley SJ, Cremasco V, Astarita JL. Immunological hallmarks of stromal cells in the tumour microenvironment. Nat Rev Immunol 2015;15(11):669-82 doi 10.1038/nri3902.

5. Joyce JA, Fearon DT. T cell exclusion, immune privilege, and the tumor microenvironment. Science 2015;348(6230):74-80 doi 10.1126/science.aaa6204.

6. Ribatti D. The concept of immune surveillance against tumors. The first theories. Oncotarget 2017;8(4):7175-80 doi 10.18632/oncotarget.12739.

7. Teng MW, Galon J, Fridman WH, Smyth MJ. From mice to humans: developments in cancer immunoediting. J Clin Invest 2015;125(9):3338-46 doi 10.1172/JCI80004.

8. Smyth MJ, Ngiow SF, Ribas A, Teng MW. Combination cancer immunotherapies tailored to the tumour microenvironment. Nat Rev Clin Oncol 2016;13(3):143-58 doi 10.1038/nrclinonc.2015.209.

9. Schreiber RD, Old LJ, Smyth MJ. Cancer immunoediting: integrating immunity's roles in cancer suppression and promotion. Science 2011;331(6024):1565-70 doi 10.1126/science.1203486.

10. Pedersen JH, Saghir Z, Wille MM, Thomsen LH, Skov BG, Ashraf H. Ground-Glass Opacity Lung Nodules in the Era of Lung Cancer CT Screening: Radiology, Pathology, and Clinical Management. Oncology (Williston Park) 2016;30(3):266-74.

11. Xu-Monette ZY, Xiao M, Au Q, Padmanabhan R, Xu B, Hoe N, et al. Immune Profiling and Quantitative Analysis Decipher the Clinical Role of Immune-Checkpoint Expression in the Tumor Immune Microenvironment of DLBCL. Cancer Immunol Res 2019;7(4):64457 doi 10.1158/2326-6066.CIR-18-0439.

12. Gerdes MJ, Sevinsky CJ, Sood A, Adak S, Bello MO, Bordwell A, et al. Highly multiplexed single-cell analysis of formalin-fixed, paraffin-embedded cancer tissue. Proc Natl Acad Sci U S A 2013;110(29):11982-7 doi 10.1073/pnas.1300136110.

13. Yoshida GJ, Azuma A, Miura Y, Orimo A. Activated Fibroblast Program Orchestrates Tumor Initiation and Progression; Molecular Mechanisms and the Associated Therapeutic Strategies. Int J Mol Sci 2019;20(9) doi 10.3390/ijms20092256.

14. Pedros C, Canonigo-Balancio AJ, Kong KF, Altman A. Requirement of Treg-intrinsic CTLA4/PKCeta signaling pathway for suppressing tumor immunity. JCI Insight 2017;2(23) doi 10.1172/jci.insight.95692.

15. Tang AL, Teijaro JR, Njau MN, Chandran SS, Azimzadeh A, Nadler SG, et al. CTLA4 expression is an indicator and regulator of steady-state CD4+ FoxP3+ T cell homeostasis. J Immunol 2008;181(3):1806-13 doi 10.4049/jimmunol.181.3.1806.

16. Rao S, Gharib K, Han A. Cancer Immunosurveillance by T Cells. Int Rev Cell Mol Biol 2019;342:149-73 doi 10.1016/bs.ircmb.2018.08.001.

17. Thommen DS, Schumacher TN. T Cell Dysfunction in Cancer. Cancer Cell 2018;33(4):547-62 doi 10.1016/j.ccell.2018.03.012.

18. Lemos H, Huang L, Prendergast GC, Mellor AL. Immune control by amino acid catabolism during tumorigenesis and therapy. Nat Rev Cancer 2019;19(3):162-75 doi 10.1038/s41568-019-0106-z.

19. Brody R, Zhang Y, Ballas M, Siddiqui MK, Gupta P, Barker C, et al. PD-L1 expression in advanced NSCLC: Insights into risk stratification and treatment selection from a 
Altorki et al

systematic literature review. Lung Cancer 2017;112:200-15 doi 10.1016/j.lungcan.2017.08.005.

20. Bonaventura P, Shekarian T, Alcazer V, Valladeau-Guilemond J, Valsesia-Wittmann S, Amigorena S, et al. Cold Tumors: A Therapeutic Challenge for Immunotherapy. Front Immunol 2019;10:168 doi 10.3389/fimmu.2019.00168.

21. Di Modugno F, Colosi C, Trono P, Antonacci G, Ruocco G, Nistico P. 3D models in the new era of immune oncology: focus on T cells, CAF and ECM. J Exp Clin Cancer Res 2019;38(1):117 doi 10.1186/s13046-019-1086-2.

22. Vinay DS, Ryan EP, Pawelec G, Talib WH, Stagg J, Elkord E, et al. Immune evasion in cancer: Mechanistic basis and therapeutic strategies. Semin Cancer Biol 2015;35 Suppl:S185-S98 doi 10.1016/j.semcancer.2015.03.004.

23. Teixeira VH, Pipinikas CP, Pennycuick A, Lee-Six H, Chandrasekharan D, Beane J, et al. Deciphering the genomic, epigenomic, and transcriptomic landscapes of pre-invasive lung cancer lesions. Nat Med 2019;25(3):517-25 doi 10.1038/s41591-018-0323-0.

24. Mascaux C, Angelova M, Vasaturo A, Beane J, Hijazi K, Anthoine G, et al. Immune evasion before tumour invasion in early lung squamous carcinogenesis. Nature 2019;571(7766):570-5 doi 10.1038/s41586-019-1330-0.

25. Lavin Y, Kobayashi S, Leader A, Amir ED, Elefant N, Bigenwald C, et al. Innate Immune Landscape in Early Lung Adenocarcinoma by Paired Single-Cell Analyses. Cell 2017;169(4):750-65 e17 doi 10.1016/j.cell.2017.04.014.

26. Chen H, Carrot-Zhang J, Zhao Y, Hu H, Freeman SS, Yu S, et al. Genomic and immune profiling of pre-invasive lung adenocarcinoma. Nat Commun 2019;10(1):5472 doi 10.1038/s41467-019-13460-3.

27. Ghandili S, Bardenhagen J, Izbicki JR. Pancreatic Metastasis from Endometrial Carcinoma. J Gastrointest Surg 2019;23(2):377-8 doi 10.1007/s11605-018-3934-3.

28. Tauriello DVF, Palomo-Ponce S, Stork D, Berenguer-Llergo A, Badia-Ramentol J, Iglesias $\mathrm{M}$, et al. TGFbeta drives immune evasion in genetically reconstituted colon cancer metastasis. Nature 2018;554(7693):538-43 doi 10.1038/nature25492.

29. Sanchez-Paulete AR, Teijeira A, Cueto FJ, Garasa S, Perez-Gracia JL, Sanchez-Arraez $\mathrm{A}$, et al. Antigen cross-presentation and T-cell cross-priming in cancer immunology and immunotherapy. Ann Oncol 2017;28(suppl_12):xii74 doi 10.1093/annonc/mdx727.

30. Beatty GL, Winograd R, Evans RA, Long KB, Luque SL, Lee JW, et al. Exclusion of T Cells From Pancreatic Carcinomas in Mice Is Regulated by Ly6C(low) F4/80(+) Extratumoral Macrophages. Gastroenterology 2015;149(1):201-10 doi 10.1053/j.gastro.2015.04.010.

31. Gil Del Alcazar CR, Huh SJ, Ekram MB, Trinh A, Liu LL, Beca F, et al. Immune Escape in Breast Cancer During In Situ to Invasive Carcinoma Transition. Cancer Discov 2017;7(10):1098-115 doi 10.1158/2159-8290.CD-17-0222.

32. Feig C, Jones JO, Kraman M, Wells RJ, Deonarine A, Chan DS, et al. Targeting CXCL12 from FAP-expressing carcinoma-associated fibroblasts synergizes with antiPD-L1 immunotherapy in pancreatic cancer. Proc Natl Acad Sci U S A 2013;110(50):20212-7 doi 10.1073/pnas.1320318110. 
bioRxiv preprint doi: https://doi.org/10.1101/2020.04.17.046540; this version posted April 18, 2020. The copyright holder for this preprint (which

A.

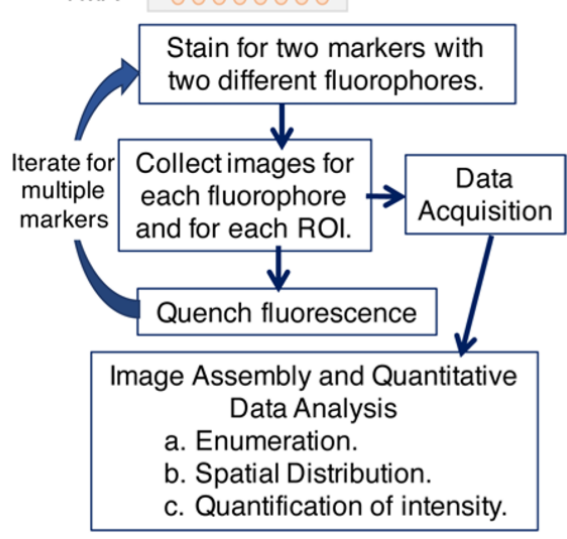

D.

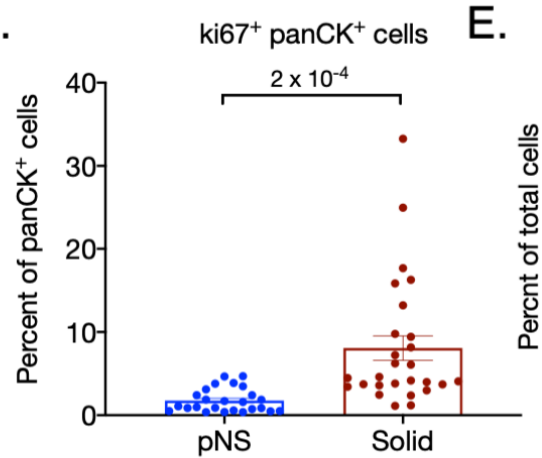

G.
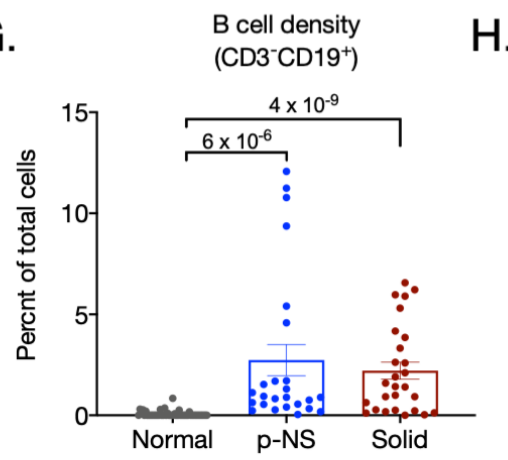

J.

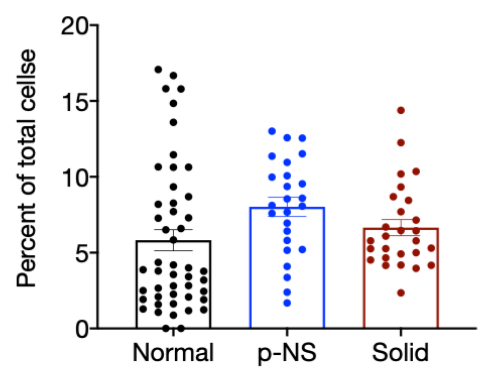

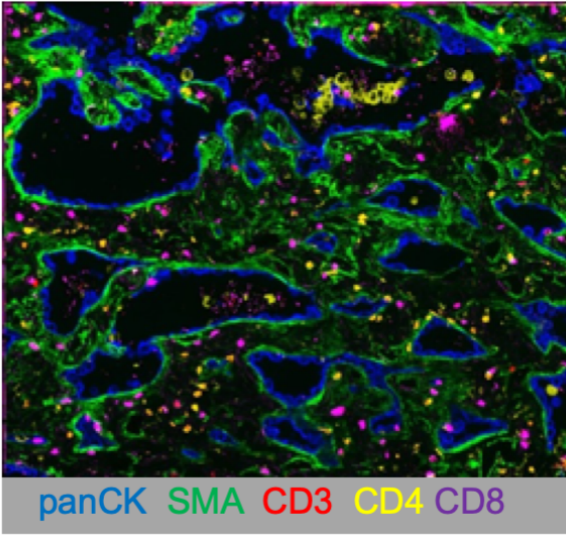
wed without permission.

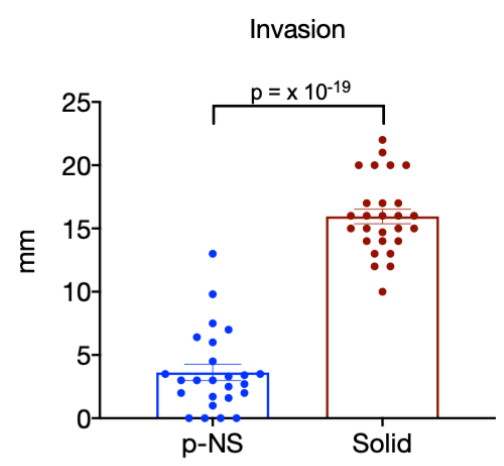

F. T cell density $\left(\mathrm{CD}^{+}\right)$

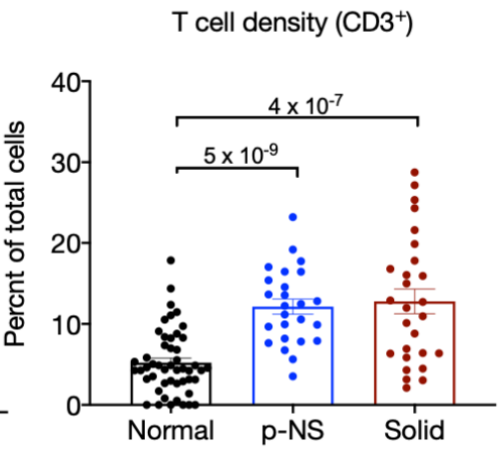

$\mathrm{H}$.

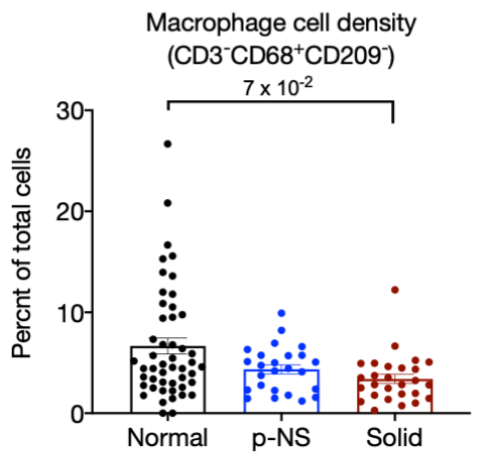

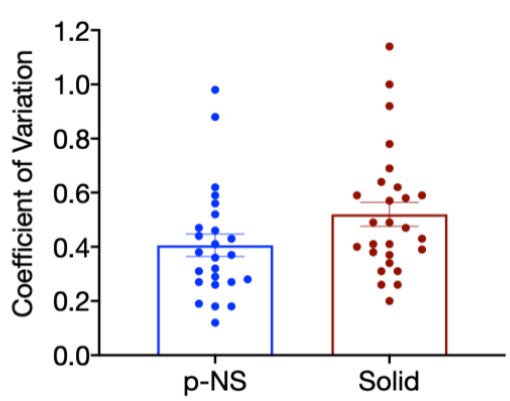

Dendritic cell density (CD3-CD209+ ${ }^{+}$CD68-)

I.

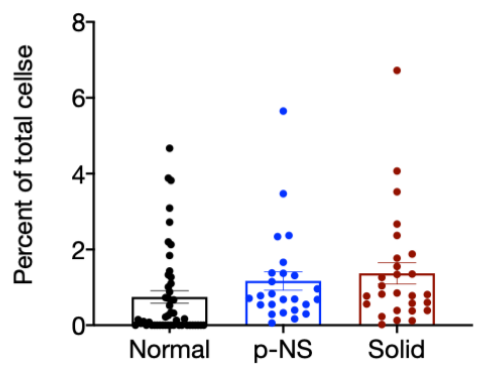

Figure 1. Immunofluorescence immune profiling. A. Cartoon of Neogenomics iterative, quantitative immunofluorescence platform. B. Representative Neogenomics pseudo-colored multiplex image, 200x magnification. Each channel scaled for purpose of presentation. C. Cancer cell invasion of the p-NS and solid tumor groups. D. Percent of panCK+ cells that are $\mathrm{ki}^{+} 7^{+}$. E. Density of $\mathrm{CD} 3^{+}$cells determined as the percentage of total cells per ROI. $\mathbf{F}$ Coefficient of variations of $\mathrm{CD}^{+}$cell densities of the 6 ROls per tumor of the p-NS and solid groups. G. Density of $\mathrm{B}$ cells (CD3-CD19+ cells) determined as the percentage of total cells per ROI. H. Density of macrophages (CD68 ${ }^{+} \mathrm{CD} 3^{-}$ CD209- cells) determined as the percentage of total cells per ROI. I. Density of dendritic cells (CD209+CD3-CD68- cells determined as the percentage of total cells per ROI. J. Density of fibroblasts (CD3- panCK- SMA ${ }^{+}$) determined as the percentage of total cells per ROI. In all panels the symbols for normal tissue are data from a single ROI per sample, whereas in the p-NS and solid groups each symbol is the mean of 3 to 6 ROls per tumor. Total cells were determined by DAPI stained nuclei per ROI. The group means \pm SEM are shown. Statistically significant differences are noted. Student's $t$ tests, unpaired. All $p$ values shown are significant based on Benjamini-Hochberg control for false discovery at an alpha of 0.05 . 
bioRxiv preprint doi: https://doi.org/10.1101/2020.04.17.046540; this version posted April 18, 2020. The copyright holder for this preprint (which was not certified by peer review) is the author/funder. All rights reserved. No reuse allowed without permission.
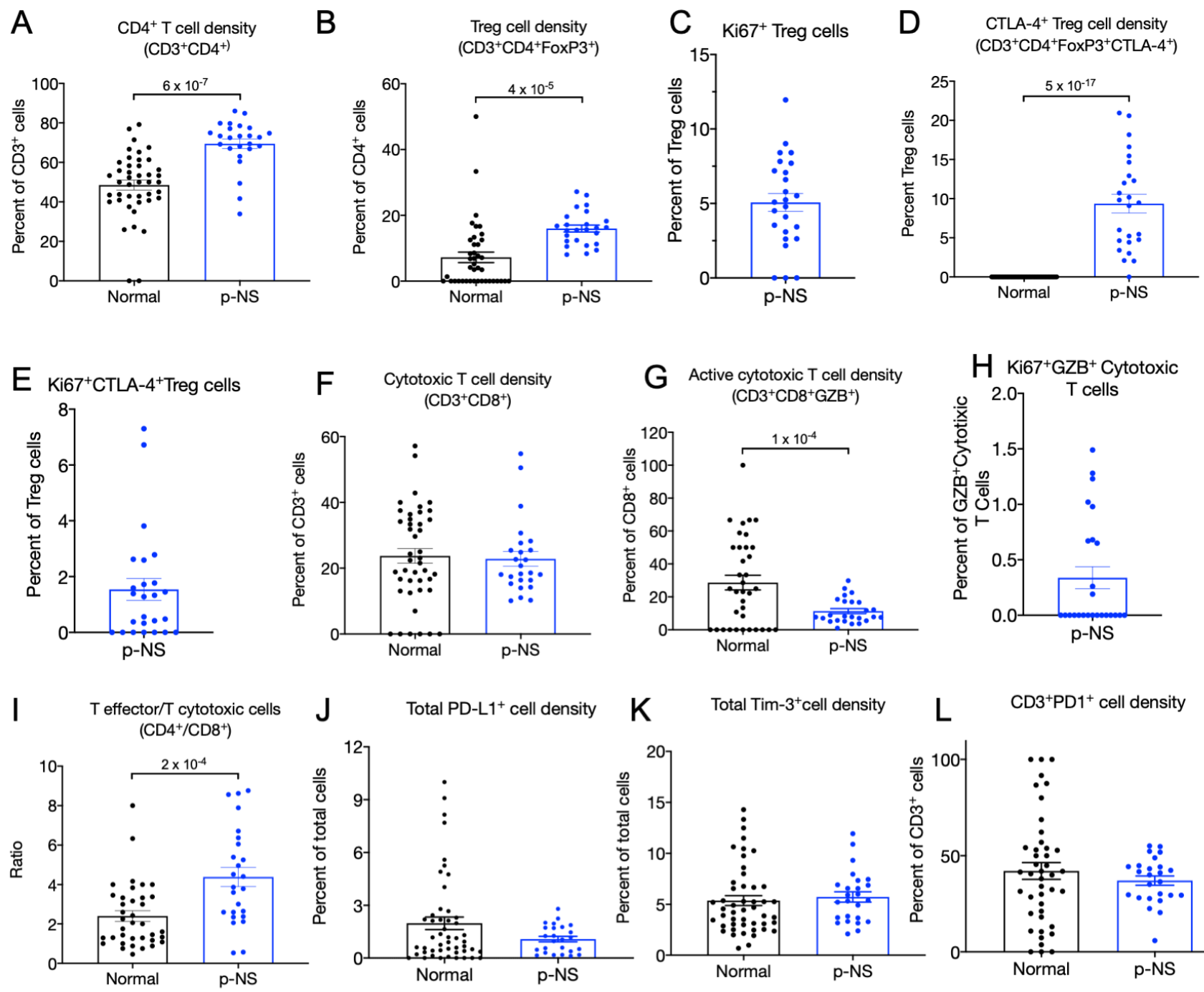

L $\quad \mathrm{CD}^{+}{ }^{\mathrm{PD}} 1^{+}$cell density
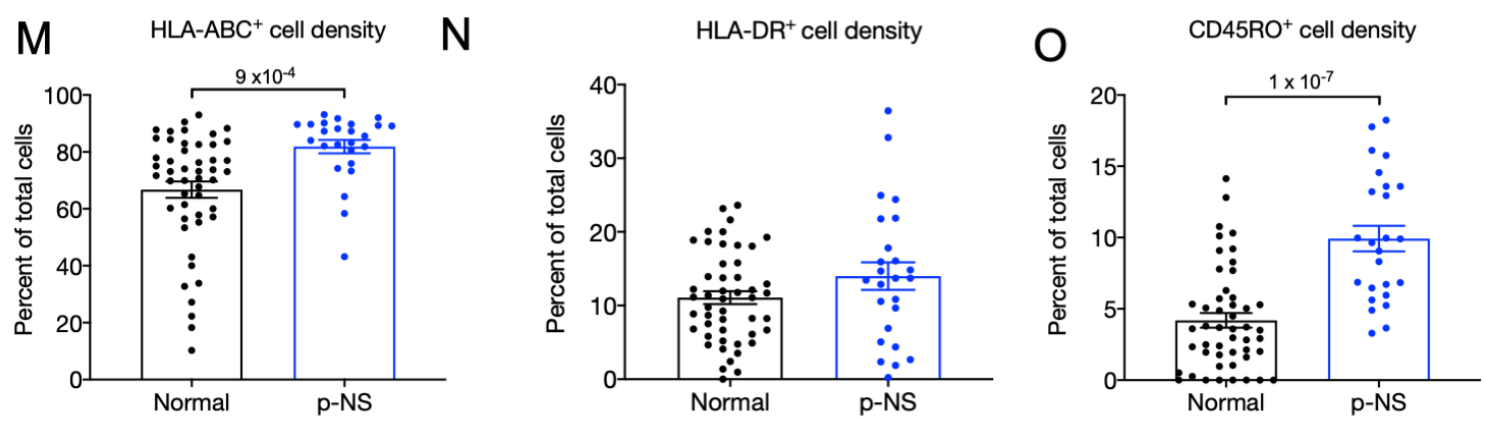

Figure 2. T cell composition. A. Densities of $\mathrm{CD} 4^{+}$cells determined as percentage of $\mathrm{CD} 3^{+}$cells. B. Treg cell densities $\left(\mathrm{CD}^{+} \mathrm{CD}^{+}{ }^{+} \mathrm{FoxP}^{+}\right)$determined as the percentage of $\mathrm{CD}^{+}{ }^{+} \mathrm{CD} 4^{+}$cells. C. Percent of Tregs in $\mathrm{p}-\mathrm{NS}$ tumor group that are $\mathrm{Ki}^{+} 7^{+}$. D. CTLA-4 $4^{+}$Treg cell densities $\left(\mathrm{CD}^{+} \mathrm{CD} 4^{+} \mathrm{FoxP} 3^{+} \mathrm{CTLA}-4^{+}\right)$as the percentage of $\mathrm{CD}^{+}{ }^{+} \mathrm{CD} 4^{+} \mathrm{FoxP}^{+}$cells. E. Percent of CTLA-4 $4^{+}$Tregs in p-NS tumor group that are Ki67+ . F. Cytotoxic T cell densities $\left(\mathrm{CD} 3+\mathrm{CD} 8^{+}\right)$determined as the percentage of $\mathrm{CD}^{+}$cells. $\mathbf{G}$. Active cytotoxic T cells densities $\left(\mathrm{CD} 3^{+} \mathrm{CD} 8^{+} \mathrm{GZB}^{+}\right)$determined as the percentage of $\mathrm{CD} 3^{+} \mathrm{CD} 88^{+}$cells. GZB, granzyme B. H. Percent of active cytotoxic T cells in p-NS tumor group that are Ki67 ${ }^{+}$. I. Ratios per tumor of Treg cells $\left(\mathrm{CD}^{+}{ }^{+} \mathrm{CD}^{+} \mathrm{FoxP3}^{+}\right.$) to cytotoxic T cells $\left(\mathrm{CD} 3+\mathrm{CD} 8^{+}\right)$. J. Total PD-L1 $1^{+}$cell densities as a percentage of total cells. K. Total Tim $-3^{+}$cell densities determined as a percentage of total cells per ROI. L. Total PD1 ${ }^{+}$cells densities determined as a percentage of total cells per ROI. M. Total HLA-ABC+ cell densities determined as a percent of total cells per ROI. N. Total HLA-DR ${ }^{+}$cell densities determined as a percentage of total cells per ROI. O. Total CD45RO+ cell densities determined as a percentage of total cells per ROI. In each comparison total cell numbers are defined by the number of DAPI stained nuclei per ROI. In all panels each normal tissue symbol is the cell density from a single $\mathrm{ROI}$ per sample, whereas in the p-NS group each symbol is the mean of 3 to 6 ROls per tumor. The means \pm SEM are shown for each group. Statistically significant differences are noted. Student's T test, unpaired. All p values shown are significant based on Benjamini-Hochberg control for false discovery at an alpha of 0.05 . 
bioRxiv preprint doi: https://doi.org/10.1101/2020.04.17.046540; this version posted April 18, 2020. The copyright holder for this preprint (which was not certified by peer review) is the author/funder. All rights reserved. No reuse allowed without permission.

A

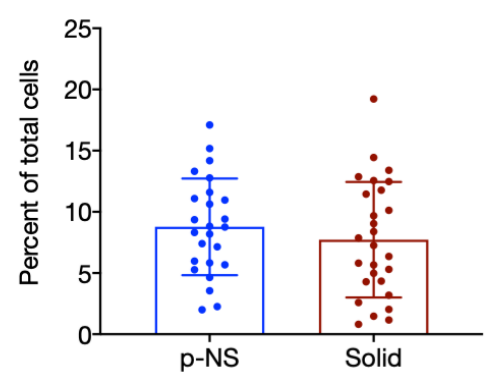

D $\begin{gathered}\mathrm{KI}^{+} 7^{+} \text {Treg cells } \\ \left(\mathrm{CD}^{+} \mathrm{CD}^{+}{ }^{+} \mathrm{Foxp}^{+}{ }^{\mathrm{k} i 67^{+}}\right)\end{gathered}$

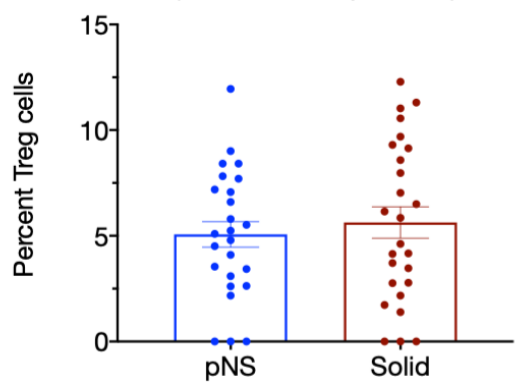

G
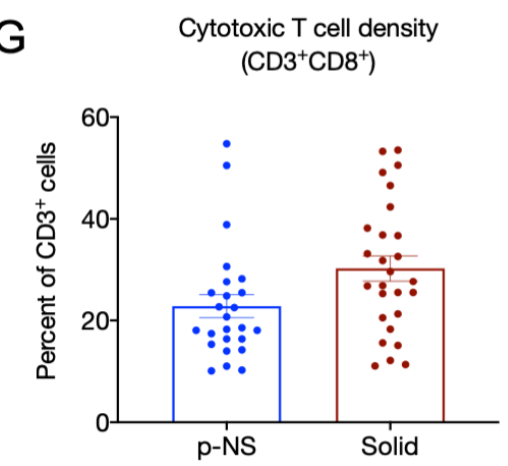

B

$\mathrm{CD}^{+} \mathrm{T}$ cell density $\left(\mathrm{CD}^{+} \mathrm{CD}^{+}\right)$

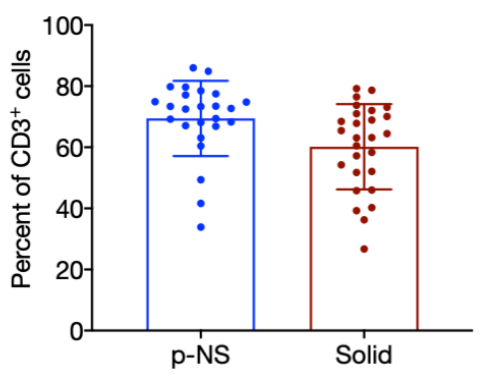

$\mathrm{E}$

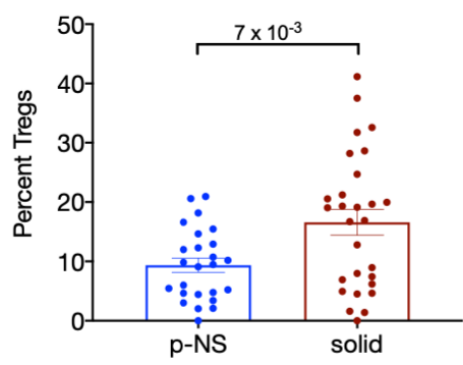

$\mathrm{H}$

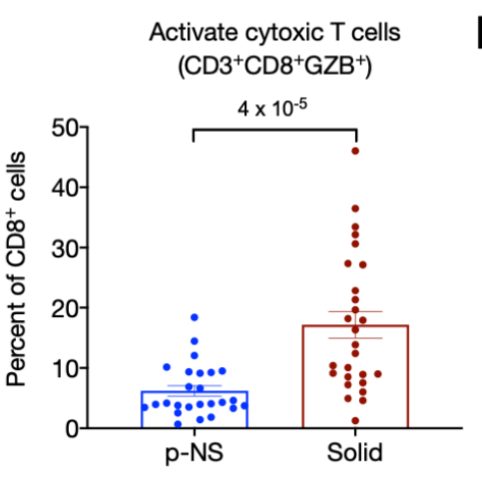

C $\quad \begin{gathered}\text { Treg cell density } \\ \left(\mathrm{CD}^{+} \mathrm{CD}^{+} \mathrm{FoxP}^{+}\right)\end{gathered}$

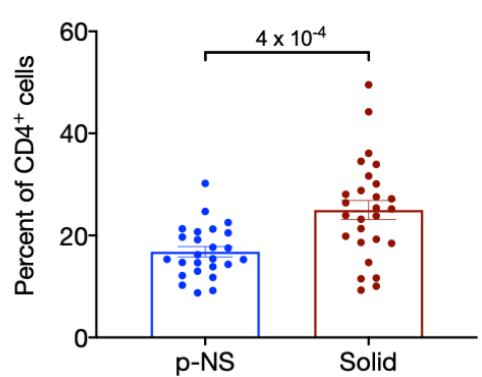

F

Cytotoxic T cell density $\left(\mathrm{CD}^{+}{ }^{+} \mathrm{CD} 8^{+}\right)$

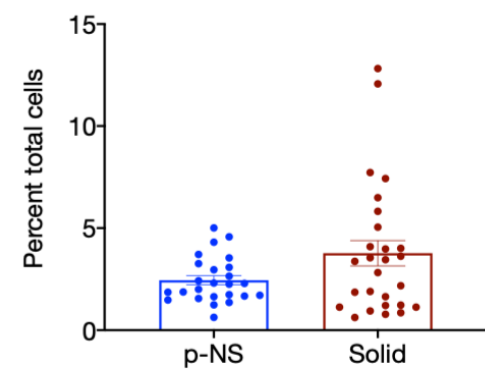

Ki67+ Active CD8 cells $\left(\mathrm{CD}^{+}{ }^{+} \mathrm{CD} 8^{+} \mathrm{GZB}^{+} \mathrm{ki67} 7^{+}\right)$

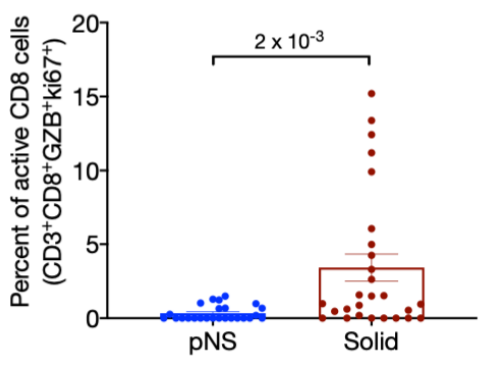

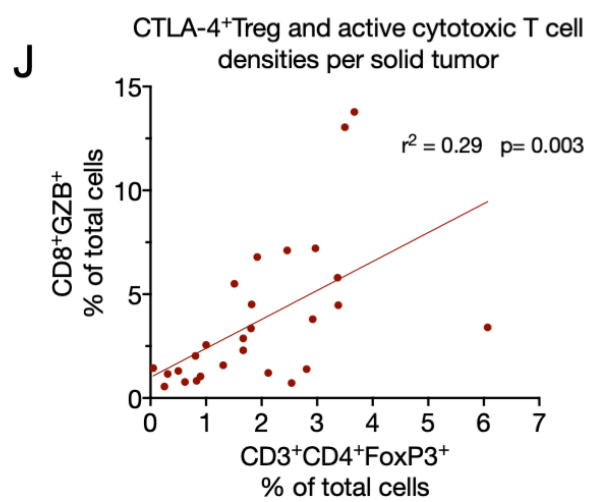

Figure 3. T cell compositions of p-NS and Solid tumors. A. CD4 ${ }^{+}$cell densities determined as a percentage of total cells per ROI. B. CD4 ${ }^{+}$cell densities determined as a percentage of $\mathrm{CD}^{+}$cells. C. Treg cell densities $\left(\mathrm{CD}^{+}{ }^{+} \mathrm{CD} 4^{+} \mathrm{FoxP}^{+}\right)$determined as a percentage of $\mathrm{CD} 4^{+}$cells. D. ki67 ${ }^{+}$Treg cell densities $\left(\mathrm{CD}^{+}{ }^{+} \mathrm{CD} 4^{+}{ }^{+} \mathrm{FxP}^{+}{ }^{+} \mathrm{ki} 67^{+}\right)$determined as a percentage of Treg cells. E. CTLA-4 ${ }^{+}$Treg cell densities $\left(\mathrm{CD}^{+}{ }^{+} \mathrm{CD} 4^{+} \mathrm{FoxP} 3^{+} \mathrm{CTLA}-4^{+}\right)$determined as a percentage of Treg cells. F. Cytotoxic T cell densities $\left(\mathrm{CD} 3^{+} \mathrm{CD} 8^{+}\right)$ determined as a percentage of total cells per ROI. G. Cytotoxic T cell densities $\left(\mathrm{CD} 3^{+} \mathrm{CD} 8^{+}\right)$determined as a percentage of $\mathrm{CD}^{+}$cells. H. Active cytotoxic T cell densities $\left(\mathrm{CD} 3^{+} \mathrm{CD} 8^{+} \mathrm{GZB}^{+}\right)$determined as a percentage of $\mathrm{CD}^{+}{ }^{+} \mathrm{CD} 8{ }^{+}$cells. GZB, granzyme B. I. ki67 ${ }^{+}$active $\mathrm{CD} 8+$ cell $\left(\mathrm{CD} 3^{+} \mathrm{CD} 8^{+} \mathrm{GZB}^{+} \mathrm{ki}^{+} 7^{+}\right)$densities determined as a percentage of $\mathrm{CD}^{+} \mathrm{CD} 8^{+}$cells. J. Correlation of $\mathrm{CTLA}-4^{+}$Treg $\left(\mathrm{CD} 3^{+} \mathrm{CD} 4^{+} \mathrm{FoxP} 3^{+} \mathrm{CTLA}-4^{+}\right)$and active cytotoxic $\mathrm{T}$ cell $\left(\mathrm{CD}^{+} \mathrm{CD} 8^{+} \mathrm{GZB}^{+}\right)$densities as percentages of total cells per ROI. The $p$ value is for the difference in the slope of the correlation line from 0 . In each panel the symbols are the means of 3 to 6 ROls per tumor. The means \pm SEM are shown for each group. Statistically significant differences are noted. Students $T$ test, unpaired. All $p$ values shown are significant based on Benjamini-Hochberg control for false discovery at an alpha of 0.05. 

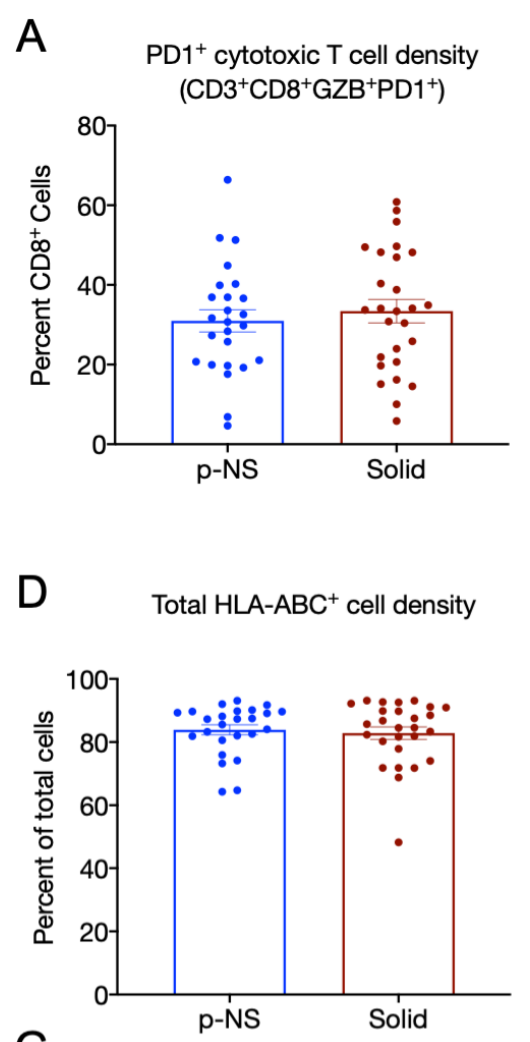

G

$\mathrm{IDO}^{+}$cell density

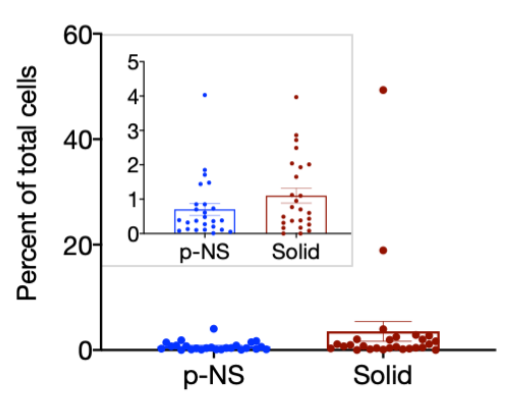

B

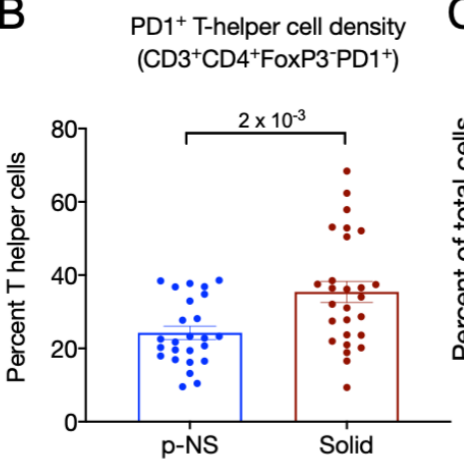

$E$

HLA-DR ${ }^{+}$macrophage density $\left(\mathrm{CD}^{+}{ }^{+} \mathrm{CD} 68^{+} \mathrm{CD} 209^{-} \mathrm{HLA}^{\left.-\mathrm{DR}^{+}\right)}\right.$

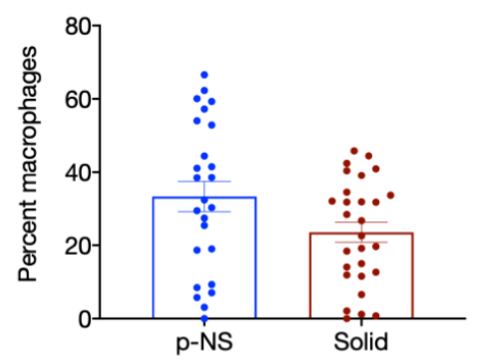

$\mathrm{H}$

Arginase $^{+}$cell density

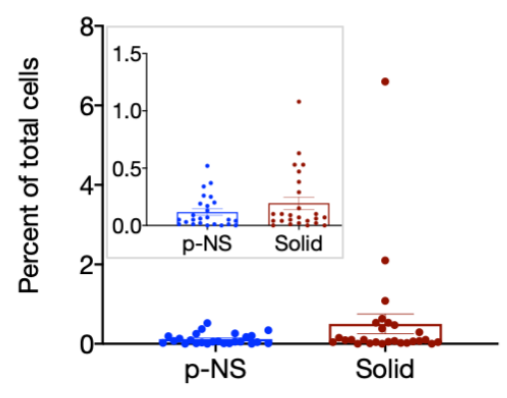

C Total Tim- $3^{+}$cell density

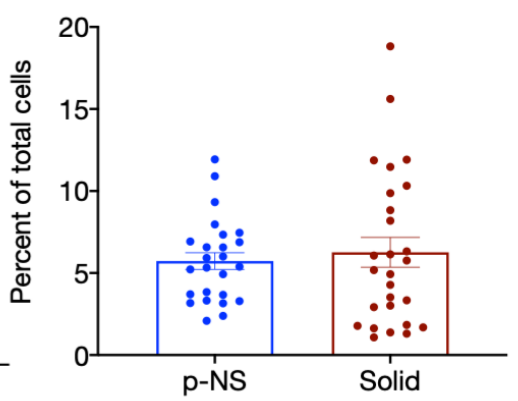

F $\quad \mathrm{HLA}^{-\mathrm{DR}^{+} \text {dendritic cell density }}$ (CD3-CD209 ${ }^{+}$CD68-HLA-DR ${ }^{+}$cells

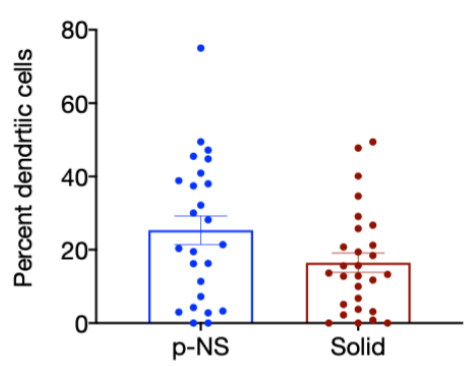

Figure 4. $T$ cell activation states. A. $P D 1^{+}$cytotoxic $T$ cell densities determined as a percentage of $\mathrm{CD} 8+$ cells. B. PD1 ${ }^{+} \mathrm{T}$ helper cell $\left(\mathrm{CD} 3^{+} \mathrm{CD} 4^{+} \mathrm{FoxP} 3^{-}\right)$densities determined as a percentage of $\mathrm{T}$ helper cells. C. Total $\mathrm{TIM}^{+}$cell densities. D. Total HLA-ABC ${ }^{+}$cell densities determined as a percentage of total cells per ROI. E. HLA-DR ${ }^{+}$macrophage densities determined as a percentage of total macrophages (CD3-CD68 ${ }^{+}$CD209-). F. HLA-DR ${ }^{+}$dendritic cell densities as percentage of dendritic cells (CD3-CD209 ${ }^{+}$CD68-). G. IDO ${ }^{+}$cell densities determined as a percentage of total cells. Inset, y axis expanded. H. Arginase ${ }^{+}$cell densities determined as a percentage of total cells. Inset, y axis expanded. In all panels each symbol is the mean of 3 ROls per tumor. The means \pm SEM are shown for each group. Total cells determined by $\mathrm{DAPI}^{+}$nuclei. Statistically significant differences are noted. Students $\mathrm{T}$ test, unpaired. All $p$ values shown are significant based on Benjamini-Hochberg control for false discovery at an alpha of 0.05 . 
A

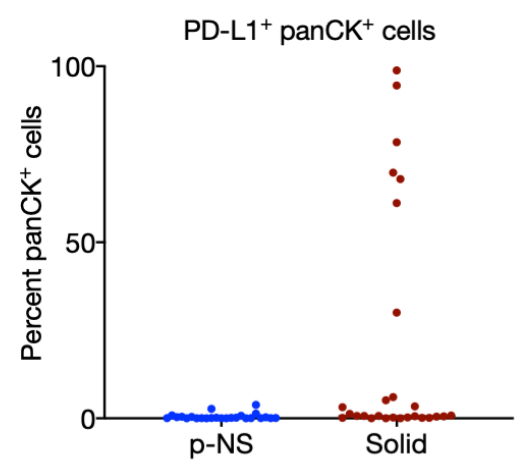

D
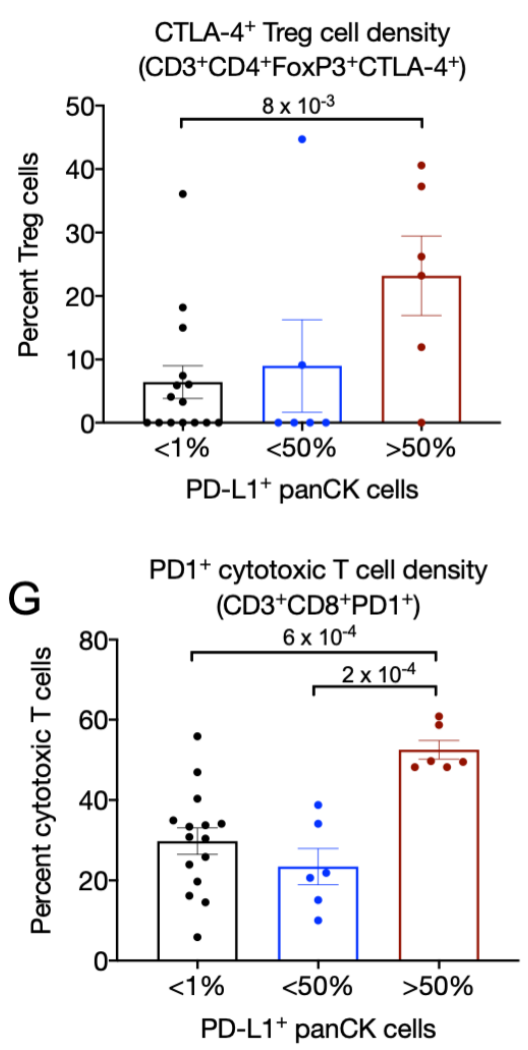

B

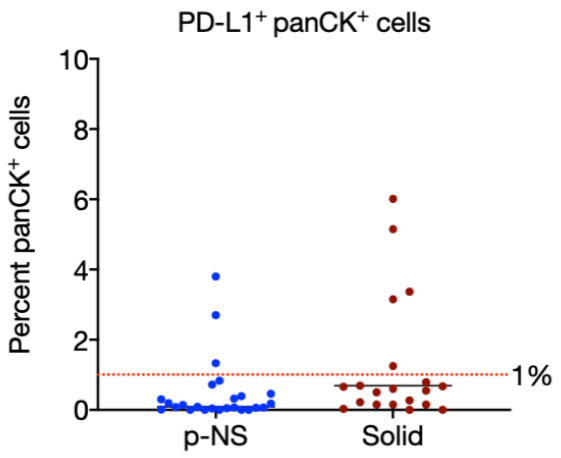

E

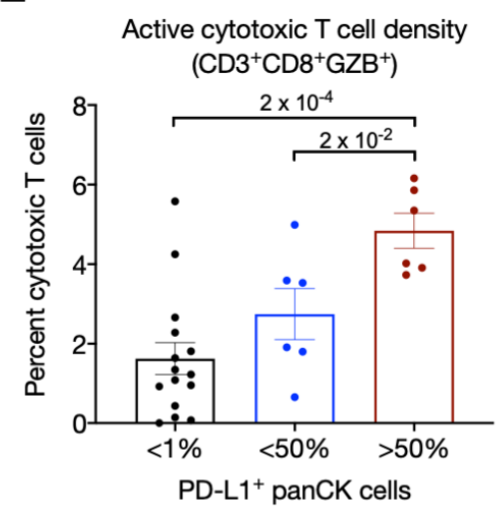

$\mathrm{H}$

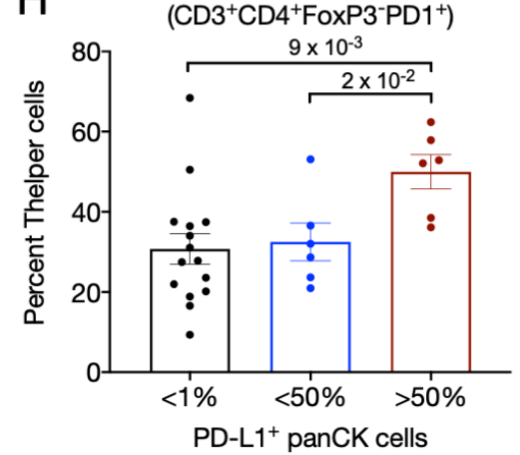

C CD3

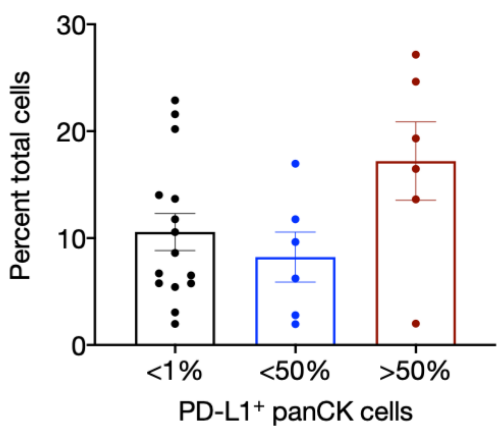

$\mathrm{F}$

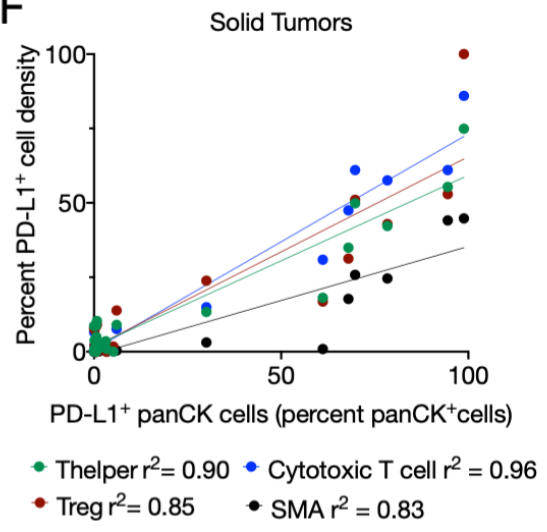

I $\mathrm{PD1}{ }^{+} \mathrm{T}$ reg cell desnity $\left(\mathrm{CD}^{+}{ }^{+} \mathrm{CD} 4^{+} \mathrm{FoxP}^{+}{ }^{+} \mathrm{PD} 1^{+}\right)$

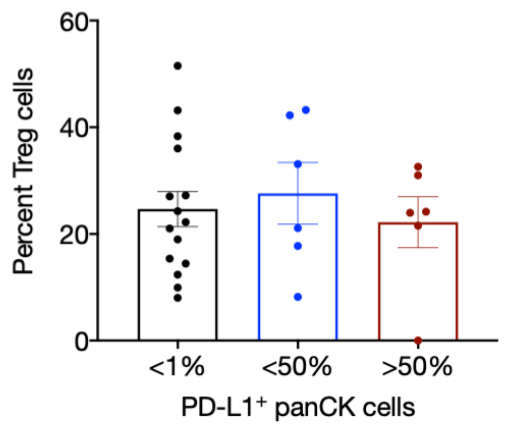

Figure 5. Immune profile linked to PD-L1 expression. A. PD-L1+panCK ${ }^{+}$cells as a percentage of panCK ${ }^{+}$cells. B. PD-L1+ ${ }^{+}$panCK ${ }^{+}$cells, percent of panCK ${ }^{+}$cells, on expanded $y$-axis to visualize differences among the low PD-L1 expressing tumors. The red dotted line is at 1\% PD-L1+panCK cells. C., D., \& E. Densities of $\mathrm{CD} 3^{+}$cells, CTLA- $4^{+}$Treg cells $\left(\mathrm{CD} 3^{+} \mathrm{CD} 4^{+} \mathrm{FoxP} 3^{+} \mathrm{CTLA}-4^{+}\right)$and active cytotoxic T cells $\left(\mathrm{CD} 3^{+} \mathrm{CD} 8^{+} \mathrm{GZB}^{+}\right)$in the 3 subcategories of solid tumors segregated by panCK ${ }^{+} \mathrm{PD}-\mathrm{L} 1^{+}$ expression, respectively. F. Correlation of panCK PD-L1+ expression and PD-L1 expression in Treg cells $\left(\mathrm{CD}^{+} \mathrm{CD}^{+} \mathrm{FoxP}^{+}\right)$, Thelper cells $\left(\mathrm{CD} 3^{+} \mathrm{CD} 4^{+} \mathrm{FoxP} 3^{-}\right)$, cytotoxic $\mathrm{T}$ cells $\left(\mathrm{CD} 3^{+} \mathrm{CD} 8^{+}\right)$and $\alpha \mathrm{SMA}^{+}$cells. Correlation values $\left(\mathrm{r}^{2}\right)$ are shown. G., H., and I. PD1 ${ }^{+}$Thelper cells $\left(\mathrm{CD} 3^{+} \mathrm{CD} 4^{+} \mathrm{FoxP3}-\mathrm{PD} 1^{+}\right)$, PD1 ${ }^{+}$ cytotoxic $\mathrm{T}$ cells $\left(\mathrm{CD}^{+}{ }^{+} \mathrm{CD} 8^{+} \mathrm{PD} 1^{+}\right)$and $\mathrm{PD} 1^{+}$Treg cells $\left(\mathrm{CD}^{+} \mathrm{CD} 4^{+} \mathrm{FoxP} 3^{+} \mathrm{PD} 1^{+}\right)$in the 3 subcategories of solid tumors segregated by panCK ${ }^{+} \mathrm{PD}-\mathrm{L} 1^{+}$expression, respectively. In all panels each symbol is the mean of 3 ROls per tumor. The means \pm SEM are shown for each group. Students $T$ test, unpaired. Statistically significant differences are noted. All $p$ values shown are significant based on BenjaminiHochberg control for false discovery at an alpha of 0.05 . 
A

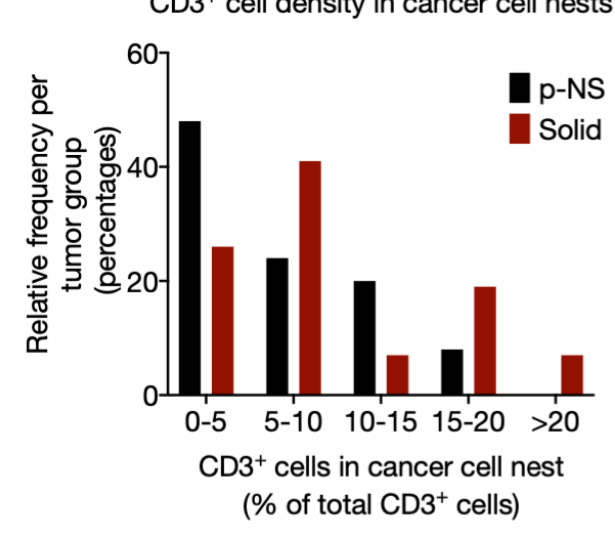

C

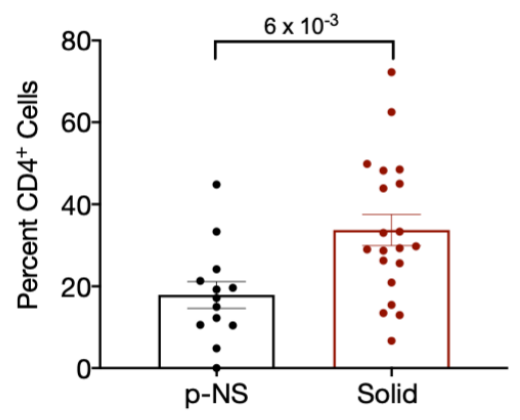

B

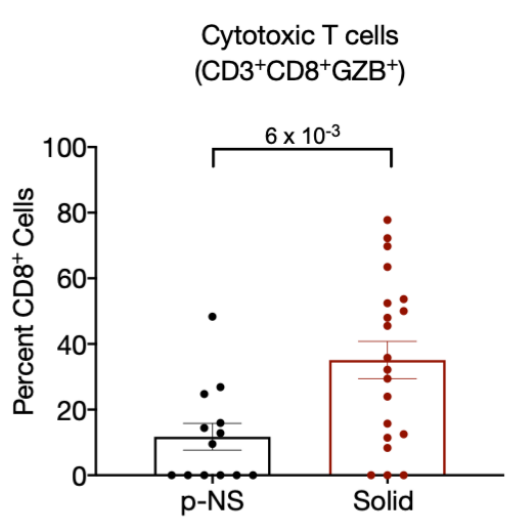

D CD3+ cells in cancer cell nests

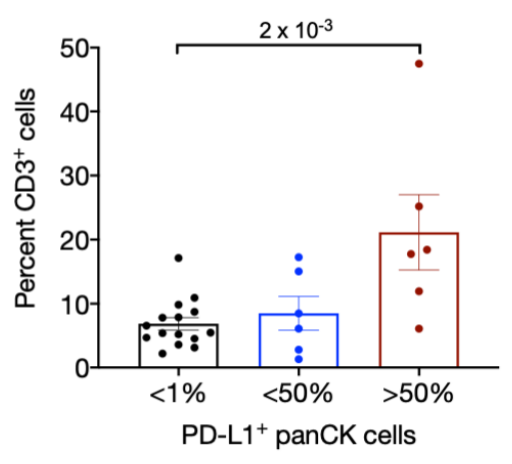

Figure 6. Distribution of $T$ cells among cancer cell nests A. Frequency distribution of $p$-NS and solid tumors based on percent of T cells located within the cancer cell nests. B. Cytotoxic $T$ cells $\left(\mathrm{CD} 3^{+} \mathrm{CD} 8^{+}\right)$within the cancer cell nests as a percent of $\mathrm{CD} 3^{+}$cells in the tumor. C. Tregs $\left(\mathrm{CD}^{+} \mathrm{CD}^{+}{ }^{+} \mathrm{FxPP}^{+}\right)$within the cancer cell nests as a percent of $\mathrm{CD} 4+$ cells in the tumor. D. T cells $\left(\mathrm{CD}^{+}\right)$within the cancer cell nests as a percentage of total T cells in the 3 subcategories of solid tumors segregated by panCK+ $\mathrm{PD}-\mathrm{L} 1^{+}$expression. In all panels $\mathrm{B}, \mathrm{C} \& \mathrm{D}$, each symbol is the mean of 3 ROls per tumor, and the means \pm SEM are shown for each group. Students $T$ test, unpaired. Statistically significant differences are noted. All $p$ values shown are significant based on Benjamini-Hochberg control for false discovery at an alpha of 0.05 . 

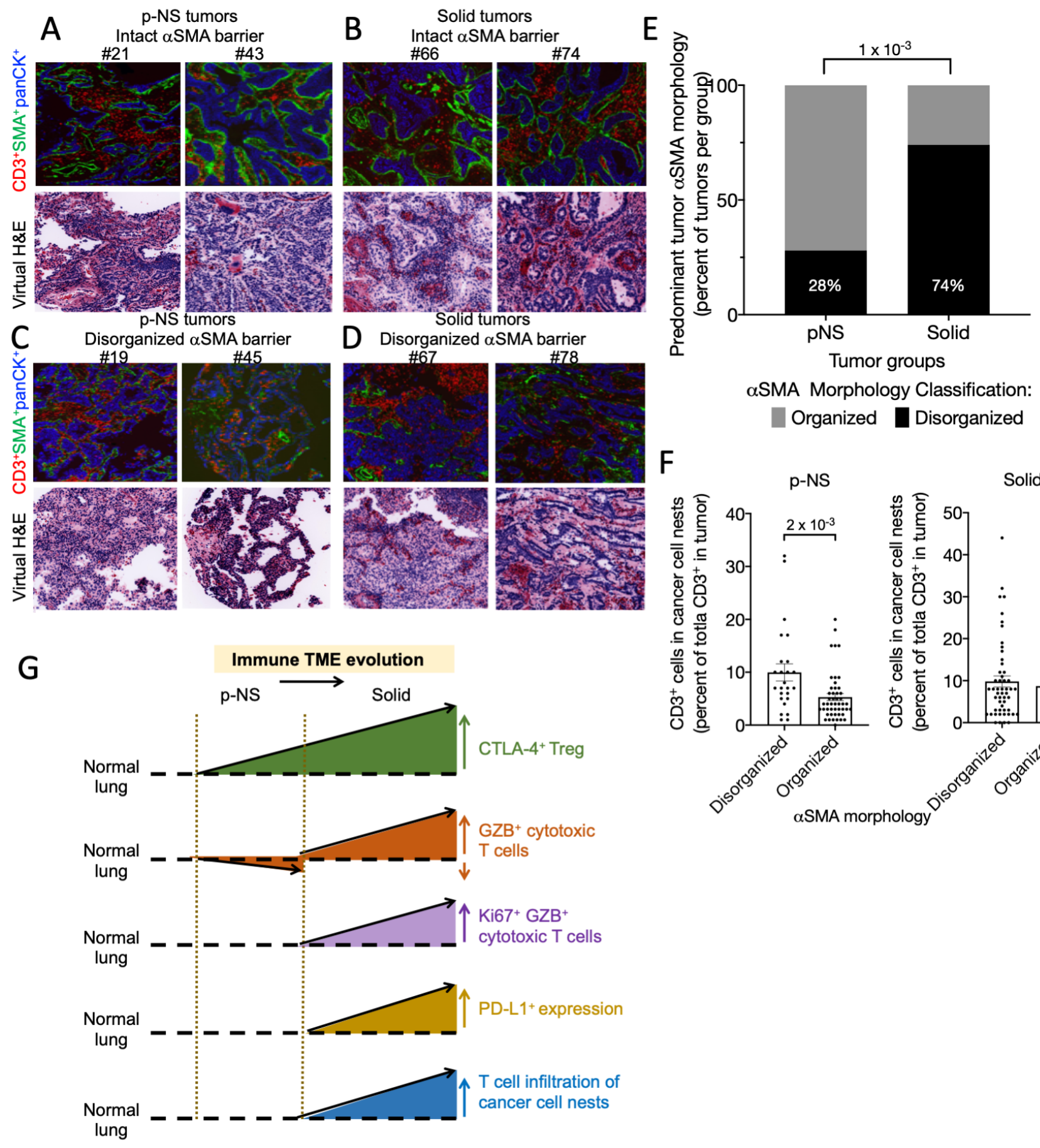

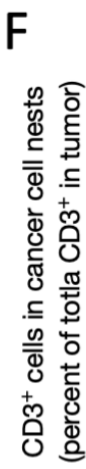

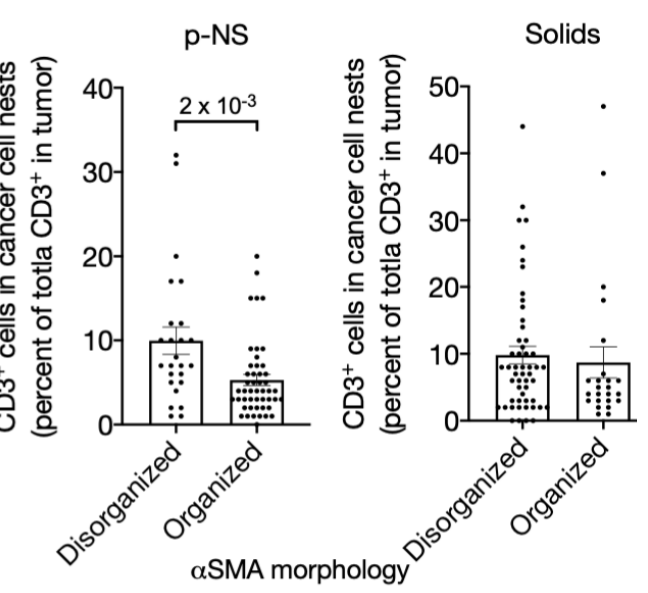

Figure 7. Relationships between tumor stroma and cancer cell nests. A. Immunofluorescence and corresponding virtual H\&E of two $p-N S$ tumors with an intact $\alpha$ SMA barrier, B. two solid tumors with an intact SMA barrier; C. two p-NS tumors with a disrupted SMA barrier; D. two p-NS tumors with a disrupted $\alpha$ SMA barrier. All images acquired at 200x magnification. E. Predominant tumor $\alpha$ SMA morphology by tumor group. $p$ value, Fischer's Exact test. F. CD3 ${ }^{+}$cell infiltration of cancer cell nest per ROI grouped by $\alpha$ SMA morphology of the ROI. Left are p-NS tumors and right Solid tumors. Statistically significant differences are noted. Unpaired Student's T test. G. Model for evolution of immune TME is stage 1A NSCLC. See text for discussion. Vertical dotted lines are separation between $\mathrm{p}-\mathrm{NS}$ and Solid groups. 


\section{Supplemental Table I: Clinical Characteristics}

A.

Age

Sex

Smoking

(Pack years)

CT Tumor size

$(\mathrm{cm})$

Path Tumor size

(cm)

SUVmax

$$
\begin{gathered}
p-N S \\
\begin{array}{c}
\text { Mean (range) } \\
n=25
\end{array}
\end{gathered}
$$

69 (53-83)

17 Female

8 Male

$25(0-110)$

$1.75(1.1-2.8)$

$1.48(0.6-2.5)$

$1.34(0-6.0)$

7 (28)

7 (28)

0 (0)

8 (32)

3 (12)

$\begin{array}{ll}\begin{array}{l}\text { Solid } \\ \text { Mean (range) } \\ \mathrm{n}=27\end{array} & \mathrm{p} \text { value } \\ 73(54-86) & \mathrm{ns} \\ \begin{array}{l}16 \text { Female } \\ 11 \text { Male }\end{array} & \mathrm{ns} \\ 41(0-130) & \mathrm{ns} \\ 1.70(0.7-3.0) & \mathrm{ns} \\ 1.94(1.1-3.0) & \\ 6.88(0-19.6) & 0.002 \\ \end{array}$

$3(11)$

10 (37)

3 (11)

10 (37)

1 (3)

Table I. A. Subject profiles. B. Mutation status. 


\section{Supplemental Table II Profiling Markers}

$\begin{array}{llll}\text { A. Antibody panel: } & & \\ \text { panCK } & \text { PD1 } & \text { CD209 } & \text { Arginase } \\ \text { CD3 } & \text { PD-L1 } & \text { HLA-ABC } & \text { Ki67 } \\ \text { CD4 } & \text { TIM3 } & \text { HLA-DR } & \\ \text { FoxP3 } & \text { CTLA-4 } & \text { aSMA } & \\ \text { CD8 } & \text { CD19 } & \text { CD45RO } & \\ \text { GZB } & \text { CD68 } & \text { IDO } & \end{array}$

B. Cell types defined by Multiplex IF:

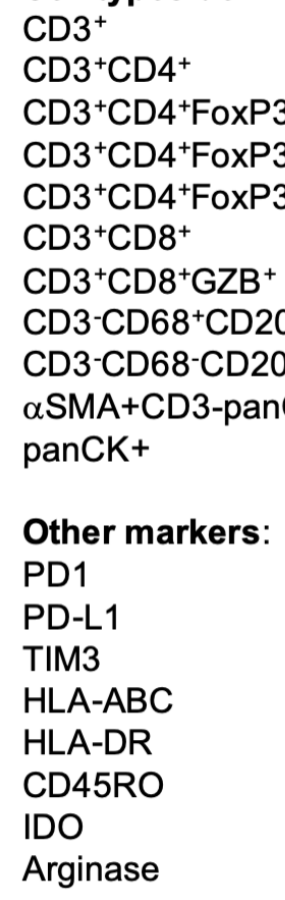

T cells

CD4+ cells

Treg cells

Activated Treg cells

T helper cells

Cytotoxic cells

Activated cytotoxic T cells

Macrophages

Dendritic cells

Fibroblasts

Cancer cells/epithelial cells

Checkpoint receptor
PD1 Checkpoint ligand
Checkpoint ligand
MHC class I
MHC class II
Memory cells
Immune suppression, tryptophan catabolic enzyme,
Immune suppression, Arginine catabolic enzyme

Table II. A. Antibody panel; B. Cell types assignments; C. Activation and other markers. 